\title{
EL MAESTRO JOSÉ FÉLIX DE RESTREPO, EL EDUCADOR DE LA GENERACIÓN DE INDEPENDENCIA DE COLOMBIA
}

\author{
Javier Ocampo López ${ }^{1}$ \\ Universidad Pedagógica y Tecnológica de Colombia \\ Grupo de Investigación HISULA \\ javierocampo11@yahoo.es
}

Recepción: 28/02/2010

Evaluación: $13 / 07 / 2010$

Aceptación: 19/07/2010

Artículo de Reflexión

\section{RESUMEN}

Este trabajo de investigación es un estudio sobre la vida y el pensamiento educativo del Dr. José Félix de Restrepo, el Maestro de la Generación de Independencia de Colombia, quien desde Popayán, Antioquia y Bogotá formó numerosos políticos de la Primera República Granadina y la Gran Colombia. Su filosofía educativa y sus ideas sobre la educación primaria, secundaria y universitaria fueron las bases estructurales para la organización y consolidación de la educación en Colombia. En la misma forma, destacamos su lucha constante por la libertad de los esclavos.

Palabras clave: Ilustración, Revolución, Independencia, Reforma Educativa, Educación Primaria, Universidades Oficiales, Esclavitud, Manumisión.

\footnotetext{
1 Doctor en historia, es profesor del Doctorado en Ciencias de la Educación de la Universidad Pedagógica y Tecnológica de Colombia - RUDECOLOMBIA, miembro de la Academia Boyacense de historia y del grupo de investigación HISULA.
} 


\title{
PROFESSOR JOSÉ FÉLIX DE RESTREPO EDUCATOR OF COLOMBIA'S INDEPENDENCE GENERATION
}

\author{
Javier Ocampo López \\ Universidad Pedagógica y Tecnológica de Colombia \\ HISULA Research Group \\ javierocampo11@yahoo.es
}

\begin{abstract}
This research work is a study on the life and the educational thoughts of Dr. José Félix of Restrepo, the Teacher of the generation of the independence of Colombia who from Popayan, Antioquia and Bogota formed a great many politicians of the first Grenadian Republic and Great Colombia (Gran Colombia). His educational philosophy and his ideas about primary, secondary and university educations were the structural bases that organised and strengthened education in Colombia. Similarly, we emphasize his relentless struggle for the enfranchisement of the slaves.
\end{abstract}

Key words:Revolution, Independence, Education Reform, Elementary Education, Universities Officers, Slavery, Manumission. 


\section{PRESENTACIÓN}

En la Historia de las Sociedades existen "Grandes Maestros", quienes con su formación filosófica, jurídica y educativa, y las sabias orientaciones a sus alumnos, se convierten en "faro de luz" de las jóvenes generaciones, que en su vigencia social actúan en el delineamiento de las nuevas ideas e instituciones, siguiendo sus enseñanzas.Uno de los grandes Maestros de la Generación Precursora de la Independencia de Colombia fue el Doctor José Félix de Restrepo (1760-1832), llamado el "Arístides colombiano" por sus luchas en la formación de los jóvenes criollos que planearon, organizaron y realizaron la independencia; por su pensamiento y acción en defensa de la Libertad Absoluta de los Esclavos; y por la organización de la educación en la Gran Colombia. Como Director de Estudios, el primer Ministro de Educación de Colombia, le correspondió el planteamiento de las ideas, el análisis y la redacción del Plan de Estudios de las primeras universidades republicanas. Se destacó como educador, filósofo, jurisconsulto, magistrado y estadista. Profesor de Filosofía, Ciencias Naturales y Experimentales (botánica, matemáticas, física, álgebra y geometría); Profesor de Derecho Civil en el Real Colegio Seminario de Popayán y en el Colegio Mayor de San Bartolomé en Santafé de Bogotá.

El Dr. José Félix de Restrepo fue un fecundo escritor. Autor de las obras: Lecciones de Metafísica, Lecciones de Lógica, Lecciones de Física, Reglamento para las Escuelas de la Provincia de Antioquia; y de varios discursos, señalando entre ellos los siguientes: "Discurso sobre la manumisión de los esclavos", "Oración para el ingreso de los estudios de Filosofía en el Seminario de Popayán", "Oración para inaugurar la cátedra de Filosofía en el Colegio de San Bartolomé", "Discurso de clausura del curso de Filosofia en el Colegio de San Bartolomé", "Observaciones sobre los últimos acontecimientos políticos de Colombia" (1831) y otros. Autor del Proyecto de Ley sobre la manumisión de los esclavos africanos y sobre los medios de redimir sucesivamente a sus padres", presentado en la República de Antioquia en 1814 al Presidente Dictador Don Juan del Corral; y del Proyecto de Manumisión, presentado al Congreso de Cúcuta en la sesión del día 28 de mayo de 1821. El Dr. Restrepo fue el más profundo defensor de la Libertad de los Esclavos y el organizador de la educación en la Gran Colombia. Le correspondió como Director de Estudios realizar la primera Reforma Universitaria, con la creación de las Universidades Centrales de Bogotá, Caracas y Quito y las Universidades Regionales : la Universidad de Boyacá en 
Tunja, la Universidad del Cauca en Popayán y la Universidad del Magdalena en Cartagena de Indias. ${ }^{2}$

\section{El maestro José Félix de Restrepo y la generación precursora}

Su nacimiento y familia. Este ilustre educador y humanista nació en Envigado (Antioquia), lugar que pertenecía entonces a la jurisdicción eclesiástica y civil de Medellín, en el año 1760. Sus padres fueron Don Vicente de Restrepo, oriundo de Rionegro y Doña Catalina Vélez. Don Vicente fue casado dos veces: en sus primeras nupcias con Doña Catalina Vélez, de cuyo matrimonio quedaron cuatro hijos varones y dos hijas; uno de ellos fue José Félix de Restrepo Vélez. En sus segundas nupcias con Doña Rita de la Granda, con quien tuvo cinco hijos. Los Restrepo eran de una familia que procedía de Asturias en el Norte de España. Ellos llegaron al Nuevo Reino de Granada en el siglo XVII y se establecieron en Antioquia. La partida de bautismo de José Félix de Restrepo, que fue encontrada en el archivo parroquial de Medellín, dice lo siguiente:

El 28 de noviembre de 1760, el Dr. Juan José Restrepo puso óleo y crisma a José Félix, antes bautizado, hijo legitimo de don Vicente Restrepo y de doña Catalina Vélez. Fueron sus padrinos don José Echeverría y doña Manuela Vélez, Doctor Esteban Antonio de Posada, Cura. ${ }^{3}$

En su familia tuvo tres hermanos, Cristóbal, Carlos y Javier; quienes se dedicaron a las ciencias eclesiásticas, cuyos títulos los obtuvieron en la Universidad de Santo Tomás en Santafé de Bogotá. Cristóbal y Carlos abrazaron el sacerdocio. El mayor fue el primer cura de Envigado. Cerca de su residencia corre la quebrada que se llama "La Doctora", nombre que se le dio por los cuatro doctores que tuvo la familia Restrepo Vélez. A mediados del siglo XVII llegó en 1652 a Antioquia, procedente de las montañas de Asturias (España), el alférez e hijodalgo Don Alonso López de Restrepo, quien se estableció en la

2 José Félix de Restrepo: Obras completas. Compilador Rafael Antonio Pinzón Garzón. Contextualizaciones y notas de Daniel Herrera Restrepo. Biblioteca Colombiana de Filosofia, Universidad de Santo Tomás. Bogotá, Departamento de Publicaciones USTA, 2002. Sobre la vida y la obra del insigne Maestro Dr.José Félix de Restrepo, véanse las siguientes obras: HERRERA RESTREPO, Daniel. (1989): El pensamiento filosófico de José Félix de Restrepo. Bogotá, Colcultura, p. 155; MONTOYA Y MONTOYA, Rafael. (1961): Obras completas de José Félix de Restrepo. Medellín, Editorial Bedout; OSPINA RODRÍGUEZ, Mariano. (1936): José Félix de Restrepo y su época. Bogotá, Publicaciones del Ministerio de Educación Nacional; RESTREPO CANAL, Carlos. (1970): José Félix de Restrepo. Jurisconsulto, humanista y hombre de Estado". Bogotá, Editorial Nelly, p. 110.

3 Partida de bautismo de José Félix de Restrepo. 28 de noviembre de 1760. En: Vida y escritos del doctor José Félix de Restrepo, recopilada por el académico Guillermo Hernández de Alba, de la Academia Colombiana de Historia. Bogotá, Imprenta Nacional, 1935, pg. 35. Sobre la familia Restrepo, véase la obra de GALLO MARTÍNEZ, Luis Álvaro. (2007): Apuntes biográficos de Restrepo. Bogotá, Editor impresor Luis Álvaro Gallo Martínez. 
vega de "La Sabaneta"; era el tatarabuelo del Dr. José Félix de Restrepo. Posteriormente llegó Don Marcos López de Restrepo, primo de Don Alonso.

Ellos eran procedentes de un lugar llamado Restrepo de la Provincia de Oviedo. Inicialmente eran López, con el nombre del lugar Restrepo; posteriormente suprimieron el López y dejaron el apellido Restrepo.

En su familia también se destacó el historiador y político Dr. José Manuel Restrepo, consagrado como el "Padre de la Historiografía colombiana", autor de la Historia de la Revolución de la República de Colombia" (6 volúmenes); "Historia de la Nueva Granada", "Diario Histórico, Diario Político y Militar, Documentos importantes de Nueva Granada, Venezuela y Colombia y otras. Entre los descendientes del Dr. José Félix de Restrepo, señalamos a los expresidentes de la República, los doctores Carlos E. Restrepo y Carlos Lleras Restrepo.Cuando nació el ilustre hijo de Envigado reinaba en España el monarca Carlos III y en el Virreinato del Nuevo Reino de Granada el Virrey José Solis. La Provincia de Antioquia tenía una población aproximada de 46.000 habitantes; sus razas eran la indígena, la española y la negra africana. Antioquia se caracterizaba por su economía de minería del oro, que se explotaba con esclavos en las minas de aluvión; las grandes haciendas agrícolas y ganaderas y por la agricultura. La situación de sus vías de comunicación era muy deficiente; para su comercio interior, los antioqueños utilizaban la arriería.

En la provincia de Antioquia había dos grandes ciudades: Santa Fe de Antioquia y Rionegro; y dos villas: Medellín y Marinilla. Otros pueblos de importancia eran Cáceres, Zaragoza y Remedios. Buriticá era la región de mayor producción de oro. En los finales del siglo XVIII se inició la colonización antioqueña hacia el sur, con la fundación de los pueblos de Sonsón, Abejorral y Aguadas, en las tierras de la antigua Villa de Santiago de Arma. En la religiosidad, Antioquia era sumamente católica; las únicas fiestas populares eran las religiosas.

\section{La generación precursora de la independencia}

En la Historia de las Generaciones colombianas, el Dr. José Félix de Restrepo perteneció a la Generación Precursora de la Independencia, que corresponde a los neogranadinos que nacieron entre los años 1760 y 1775, con vigencia social entre los años 1805 y 1820 . Fueron los criollos precursores, educados en un sistema de vigencias y creencias españolas y con un dualismo espiritual entre la Escolástica y la Ilustración. Personajes como el Dr. José Félix de Restrepo (1760), Antonio Nariño (1765), Camilo Torres (1766), José Joaquín Camacho (1766), Francisco Antonio Zea (1766), Francisco José de 
Caldas (1768), José María Cabal (1769), José María García de Toledo (1769), Frutos Joaquín Gutiérrez (1770), José Ignacio de Herrera (1770), Jorge Tadeo Lozano (1771), José Acevedo y Gómez (1773), Antonio Villavicencio (1775) y otros. A nivel de Hispanoamérica son sus coetáneos los precursores Francisco de Miranda de Venezuela; Manuel Belgrano y Mariano Moreno de Argentina; Hipólito de Unanue y Pablo de Olavide del Perú; Francisco Eugenio de Santa Cruz y Espejo de Quito; los precursores chilenos Juan de Egaña y Juan Martínez de Rozas; el precursor de Centroamérica José Cecilio del Valle; los precursores de México Francisco Javier Clavijero y Fray Servando Teresa de Mier y otros.

Esta generación se formó en un ambiente de dualismo entre la tradición teocéntrica medieval y la modernidad de la Ilustración; y el surgimiento de las ideologías, entre ellas, el Demoliberalismo. El siglo XVIII fue una época de grandes cambios, insurrecciones socio-económicas, como el movimiento de los Comuneros de Túpac Amaru en el Perú y la insurrección de los Comuneros en el Oriente del Nuevo Reino de Granada. Y en lo más profundo, el XVIII fue el siglo de las Revoluciones Mundiales: La Revolución Industrial que tuvo grandes repercusiones en lo económico y social; las Revoluciones Burguesas de Occidente, señalando en historia conectada, la independencia de los Estados Unidos, la Revolución Francesa y las revoluciones hispanoamericanas del siglo XIX. Este ambiente de cambio y revolución influyó decisivamente en la Generación Precursora de la Independencia, en la transición entre los siglos XVIII y XIX.Las luchas se presentaron alrededor del cambio, de lo teocéntrico medieval a lo antropocéntrico de la Ilustración: del gobierno monárquico de los reyes, al gobierno democrático del pueblo; del Antiguo Régimen aristocrático y señorial a la sociedad democrática, con el respeto a los Derechos del Hombre en la libertad, la igualdad, la propiedad privada, la libre empresa, el libre comercio y la seguridad. Del colonialismo con dependencia de la metrópoli española a la Independencia con el nacimiento de un nuevo Estado Nacional, democrático y republicano.

\section{El pensamiento ilustrado}

En la segunda mitad del siglo XVIII, en los años de formación del Dr. José Félix de Restrepo, influyó en Hispanoamérica el pensamiento ilustrado, cuya tendencia fue la difusión de las nuevas ideas de "la modernidad" contra la tradición y la mentalidad teocéntrica de profundas raíces medievales. Fueron sus luchas las libertades, el racionalismo y el antropocentrismo. La Revolución Industrial que se generalizó con el Mundo de Occidente influyó en la crisis de la economía mercantilista y en la vigencia del capitalismo a nivel mundial. Asimismo, dio importancia a la burguesía de industriales y comerciantes, que se opuso al 
Antiguo Régimen, a un orden monárquico, señorial y aristocrático y defendió el nuevo orden nacional, democrático y republicano.La Ilustración fue un movimiento espiritual y cultural del mundo de Occidente, el cual buscó dominar con la razón un conjunto de problemas del hombre y de la naturaleza; y cuya influencia se manifestó en lo político, cultural, social, económico y científico. La búsqueda de lo antropocéntrico, la razón de ser del Hombre en el mundo, que busca libertad, progreso e igualdad, se presentó como meta de la Ilustración. A través de ella se consolidó la doctrina política del liberalismo filosófico, con sus tesis de libertad y progreso; del utilitarismo, con sus doctrinas económicas del bienestar para las mayorías; y de la democracia, con sus ideas políticas de soberanía popular, voluntad popular y del gobierno del pueblo.

Los ilustrados tuvieron gran interés por la naturaleza, el conocimiento científico y los métodos experimentales y prácticos. Fue su pasión notable el estudio de las ciencias naturales, especialmente la botánica y las biológicas; y los estudios de la física, química, matemáticas, geometría, trigonometría, álgebra, la geografía y otras. Se fortaleció la ciencia como único camino para llegar al conocimiento verdadero y al progreso de la sociedad. En el Nuevo Reino de Granada, el ambiente científico se consolidó con la obra del Sabio José Celestino Mutis, quien en 1774 expuso en la Nueva Granada el sistema copernicano y fue el ideólogo y director de la Expedición Botánica. También con la vigencia del Plan de estudios de Moreno y Escandón que introdujo en la educación neogranadina el raciocinio y las ciencias naturales, físicas y experimentales; asimismo, el periodismo científico y las enseñanzas ilustradas. Esta influencia de la Ilustración se reflejó en las enseñanzas del Maestro de la Generación Precursora, el Dr. José Félix de Restrepo desde Popayán, Antioquia y Santafé de Bogotá.

La Ilustración consolidó la idea de los derechos del hombre y del ciudadano, propuesta por el filósofo inglés John Locke, la cual se convirtió en el símbolo de las revoluciones norteamericana, francesa e hispanoamericana. El filósofo ginebrino Juan Jacobo Rousseau defendió las ideas de la igualdad de todos los seres; la democracia y el poder supremo del pueblo en el gobierno; el contrato social, la soberanía popular y la voluntad general. Estas ideas rousonianas influyeron notablemente en el pensamiento y la acción del Maestro de la Generación Precursora, Dr. José Félix de Restrepo y en otros precursores de la independencia hispanoamericana. El filósofo Voltaire defendió la tolerancia y las libertades en todas sus dimensiones contra el dogmatismo y asimismo la libertad de cultos contra el fanatismo religioso y las supersticiones; atacó el providencialismo y difundió el antropocentrismo y el humanismo. Montesquieu en sus escritos se manifestó partidario de la libertad y la igualdad de todos los 
hombres, la separación entre la Iglesia y el Estado, la libertad de cultos, la libertad de pensamiento y de imprenta, la laización de la educación; asimismo defendió el espíritu de las leyes y la separación de los poderes públicos. Estas ideas influyeron en los precursores y libertadores de la revolución de independencia hispanoamericana y dieron las bases para la justificación de la Independencia. ${ }^{4}$

\section{Su estilo vital y formación educativa}

En este ambiente de la Ilustración se formó el Dr. José Félix de Restrepo, quien hizo sus estudios primarios en Sabaneta con su tío, el Padre Juan Cristóbal Vélez de Rivero, quien fue su mentor. De su tío aprendió el latín y el humanismo que siempre fue la fuerza espiritual de su cultura.

En 1773, a la edad de trece años, siendo aún muy joven, fue enviado a Santafé de Bogotá al Real Colegio de San Bartolomé, el más antiguo del Virreinato, el cual fue fundado en el año 1592 por el Arzobispo Bartolomé Lobo Guerrero. Cuando al joven antioqueño se le hizo el examen de rigor para entrar a la institución, fue hallado "superabundantemente ilustrado en latín", según el concepto de los examinadores, en lo cual se manifiesta la influencia de su tío el latinista, Padre Juan Cristóbal Vélez. El Rector y los conciliares del Real Colegio, después de un riguroso estudio sobre la legitimidad, limpieza de sangre, calidad, buenas costumbres y buena vista del joven Restrepo, quien había solicitado vestir la beca del Colegio, ordenaron su investidura, la cual se efectuó el 11 de octubre de 1773.

Le correspondió estudiar ciencias físicas y matemáticas, ciencias naturales, lógica y filosofía, derecho canónico clásico, derecho civil y otras materias según el nuevo Plan de estudios de Moreno y Escandón.Este Plan que consolidó la Ilustración en el Nuevo Reino de Granada a través de la educación racionalista y experimental, fue ordenado por el Virrey Manuel Guirior, en su período virreinal de 1773 a 1776 y redactado por el Fiscal de la Audiencia de Santafé, el criollo natural de Mariquita, Don Francisco Antonio Moreno y Escandón. Este plan introdujo en el país el racionalismo con los métodos experimentales, para contrarrestar la Escolástica. Se preconizó la libertad de investigación y el

\footnotetext{
4 Sobre la Ilustración véanse las siguientes obras: FRITZ, Valiavec. (1964): Historia de la Ilustración en Occidente. Madrid, Ediciones RIALP; CASSIRER, Ernest(1972): Filosofia de la Ilustración, México, Fondo de Cultura Económica; CARDIEL REYES, Raúl. (1964): Los filósofos modernos en la Independencia Latinoamericana. México, UNAM. ESCOBAR VALENZUELA, Gustavo. (1990): La Ilustración en la filosofía latinoamericana. México, Editorial Trillas. SOTO, Diana. (1995): y otros, La Ilustración en América Colonial. Madrid, Ediciones Doce Calles.
} 
eclecticismo contra el espíritu de partido. Se generalizaron las ciencias naturales, las ciencias aplicadas y experimentales; se dio importancia a los estudios de botánica, zoología, química, matemáticas, álgebra, geometría y trigonometría para habituar a los educandos al razonamiento exacto. En la misma forma, se recomendó el estudio de la Física moderna para aprovechar los nuevos descubrimientos que a diario se hacen. Las disciplinas tradicionales también aparecieron en el nuevo plan de estudios: la teología, los estudios eclesiásticos, lengua latina, filosofía, derecho canónico y otras áreas humanísticas que fueron encomendadas en los estudios superiores. Se consideró la educación como una función del Estado; y se recomendó la fundación de una Universidad pública y oficial para el Nuevo Reino de Granada. ${ }^{5}$

El Plan de estudios Moreno y Escandón tuvo vigencia en la educación colombiana entre los años de 1774 a 1778, precisamente en los años de estudio del alumno José Félix de Restrepo, quien con las nuevas orientaciones educativas recibió las influencias de la Ilustración. En el año 1778, la Junta de Estudios, estableció un nuevo Plan de Estudios, con regreso al escolasticismo. Se manifestó el dualismo cultural entre la Tradición representada en la Escolástica y la Modernidad representada en el Racionalismo y la Ilustración.

Influencia de la Expedición Botánica: Cuando estudiaba en el Real Colegio de San Bartolomé, el joven José Félix de Restrepo, dedicado a sus estudios de filosofía y jurisprudencia, recibió también las influencias del Sabio José Celestino Mutis, cuyos conocimientos en las ciencias naturales, la botánica, la física, las matemáticas y la astronomía infundían la nueva educación científica y naturalista en la juventud neogranadina. El Sabio Mutis inauguró la primera cátedra de matemáticas en el Colegio Mayor del Rosario en 1762; y en 1774 explicó la astronomía con las tesis de Copérnico, lo cual tuvo impacto en la tradición escolástica y en el Santo Oficio de la Inquisición. Años después, en 1783, el Arzobispo Virrey Antonio Caballero y Góngora acogió las nuevas ideas de la Ilustración, con las cuales fundó la Expedición Botánica del Nuevo Reino de Granada, con la dirección y orientaciones del Sabio Mutis. Así la Generación Precursora de la Independencia se formó alrededor de las nuevas ideas de la Ilustración, con sus dos Grandes Maestros: el Sabio José Celestino Mutis desde Santafé de Bogotá y el Maestro Dr.José Félix de Restrepo desde Popayán.

\footnotetext{
5 MORENO Y ESCANDÓN, Francisco. (1774-1779): "Plan de Estudios. Método provisional e intensivo de los estudios que han de observar en los Colegios de Santafé, por ahora, y hasta tanto que se erige Universidad Pública, o su Majestad no dispone otra cosa", en Boletín de Historia y Antigüedades (Bogotá), Academia Colombiana de Historia, vol. XXIII, p. 645.
}

Rhela. Vol. 14. Año 2010, pp. 9 - 60 
Culminación de sus estudios: en junio de 1776 recibió su diploma de Bachiller en Filosofía y Letras; y después de haber cursado las asignaturas en jurisprudencia, recibió el grado de Licenciado en Leyes en el año 1778. A los 18 años fue designado pasante en la cátedra de Filosofía y dos años después fue nombrado Profesor en propiedad para dicha cátedra, por el Virrey Manuel Antonio Flórez, quien tuvo conocimiento de su inteligencia. Por espacio de un año enseñó en el mismo Colegio la Filosofía aristotélica, la Moral, la Lógica, Aritmética, Geometría, Geografía, Álgebra y Metafísica. El 7 de mayo de 1780 recibió el título de Doctor en Derecho Civil en la Universidad de Santo Tomás, la institución universitaria que estaba autorizada oficialmente para conceder los títulos universitarios del doctorado.Después de culminar sus estudios en Santafé de Bogotá, cuando apenas contaba con veinte años, el joven jurisconsulto y filósofo regresó a Medellín. Entonces ya tenía fama por su ciencia y maestría para enseñar la filosofía y las ciencias naturales. En su actividad jurídica siempre defendió la inalterable disposición de la ley. Por ello, llevó como enseña la siguiente sentencia: "No debe cometerse una injusticia, aun cuando el universo se desplome". Así recomendaba a sus discípulos quien ocupó sitio de honor en los Congresos Nacionales, y llegó a ser Ministro y Presidente de la Alta Corte de Justicia y Secretario del Interior y Relaciones Exteriores de Colombia. ${ }^{6}$

\section{El Educador Dr. José Félix de Restrepo y el Real Colegio Seminario de Popayán}

La principal labor del Maestro Dr. José Félix de Restrepo fue la Educación, realizando su mayor obra pedagógica en el Real Colegio Seminario de San Francisco de Asís de Popayán. La pedagogía fue su pasión y su actividad más importante; lo que más le gustaba era enseñarles a sus alumnos y escribir importantes textos para complementar sus clases de filosofía y ciencias naturales, especialmente Física y Botánica. En sus clases se especializó en filosofía; y asimismo, dictaba los cursos de matemáticas, física, geografía e Historia del Derecho Público. En literatura también fue una autoridad. Asimismo en los diversos cursos de Derecho, propios de su actividad profesional. En la práctica forense fue discípulo del Dr. Manuel Antonio Rubianes. Le gustaba traducir textos y dictar las clases y prácticas en la Botánica y las Ciencias Naturales.

6 Véase la obra de GÓMEZ HOYOS, Rafael. (1999): La Revolución Granadina de 1810. Ideario de una Generación y de una época 1781-1821. Bogotá, Editorial Temis, 1962. 2 tomos. Asimismo, la obra de OCAMPO LÓPEZ, Javier. (1999): El proceso ideológico de la emancipación en Colombia. Bogotá, Editorial Planeta. 
Después de recibir su Título de Doctor en Derecho, el Obispo de Popayán Don Jerónimo Antonio de Obregón le ofreció la Cátedra de Filosofía para el Real Colegio Seminario. Así le expresó en la carta que le envió el 18 de mayo de 1782:

El doctor don Juan Salvador de Villa, cura de la villa de Medellín y vicario superintendente de esta provincia me escribe que habiendo propuesto a vuestra merced en mi nombre, viniese a esta ciudad de Popayán a leer la cátedra de FILOSOFÍA, que ya había leido en Santa Fe, con particular aplauso por sus notorios talentos, letras y demás apreciables prendas que le adornan, parece había vuestra merced condescendido a sus ruegos, con singular complacencia mía, porque con tal maestro aseguraré el aprovechamiento de los discípulos que puedan concurrir, entre los que hay algunos de muy buena capacidad que sería gran lástima se malograsen por falta de instrucción y cultivo... ${ }^{7}$

Durante 29 años, a partir del año 1782 hasta 1811, realizó su obra docente el Dr. José Félix de Restrepo en el Real Colegio Seminario de San Francisco de Asís de Popayán. Inicialmente durante tres años, como catedrático de Filosofía; posteriormente en 1791 se le dio la cátedra de Artes, y en 1795 fue nombrado para dictar Instituciones de Derecho Civil. Entre sus alumnos destacamos a los ideólogos patriotas Camilo Torres, Francisco José de Caldas, Francisco Antonio Zea, Miguel y Manuel de Pombo, Francisco Antonio Ulloa, Joaquín, Manuel José, Manuel María y Tomás Cipriano de Mosquera, José Hilario López, José María Obando y otros. El joven pedagogo introdujo la nueva educación de la Ilustración con las ideas racionalistas y experimentales del Plan de Estudios Moreno y Escandón; introdujo las ciencias naturales y exactas y transmitió las ideas sobre las maravillas de la naturaleza en el Nuevo Reino de Granada y en Hispanoamérica.

El Real Colegio Seminario de San Francisco de Asís de Popayán, hoy Universidad del Cauca, fue fundado por iniciativa del Señor Obispo de Popayán Fray Francisco de la Serna y Rimaga en el año 1639 y encomendado a la Compañía de Jesús a través del Padre jesuita Francisco Fuentes y el señor Deán don Francisco Vélez de Zúñiga. Los tres Franciscos pusieron el nuevo Colegio bajo la advocación de San Francisco de Asís. La Real Audiencia de Santa Fe de Bogotá, por auto del 15 de noviembre de 1640 señaló a Popayán como lugar en donde se debía fundar un Colegio de la Compañía de Jesús.

7 Carta del Obispo de Popayán Don Jerónimo Antonio de Obregón al Dr. José Félix de Restrepo, ofreciéndole la Cátedra de Filosofía para el Seminario de Popayán, en Vida y escritos del doctor José Félix de Restrepo, recopilada por el Dr. HERNÁNDEZ DE ALBA, Guillermo. óp., cit. p. 36-37.

Rhela. Vol. 14. Año 2010, pp. $9-60$ 
Cuando quedó sólida y legalmente establecida la residencia de los jesuitas en Popayán, el Obispo Francisco de la Serna y Rimaga hizo la solemne fundación del Colegio Seminario, que nació bajo la dirección de los jesuitas. Las primeras Constituciones fueron aprobadas por la Real Cédula de Felipe IV, expedida el 28 de abril de 1643. Desde su fundación quedaron unidos en un solo recinto, el Colegio de los Padres Jesuitas y el Seminario de Popayán. En su Plan de Estudios los Jesuitas tuvieron en cuenta las tres etapas de la enseñanza: las letras humanas, la filosofía y los estudios teológicos. Las Letras humanas se dividían en Gramática, Humanidades y Retórica. Inicialmente se impartió la cátedra de Gramática, repartida en la gramática ínfima, gramática media y gramática suprema; se debía aprender Sintaxis latina, Analogía griega, Prosodia Latina y la Sintaxis griega. El curso de filosofía comprendía las clases de Lógica y Metafísica general, las Matemáticas; la Cosmología y la Psicología, junto con la física y la química; la Teodicea y la Ética, con ampliación de Matemáticas y elementos de Historia natural. El primero que enseñó matemáticas y ciencias naturales fue el padre jesuita Juan de Velasco, quien trajo los dos primeros globos y la primera esfera armilar.

La financiación del Real Colegio Seminario se hizo especialmente a través de las donaciones de los fieles más ricos de la Diócesis y de varias haciendas que eran propiedad de los Jesuitas; y entre ellas, la Hacienda Gelima, que tenía la mina de oro que sirvió de base a la fundación del Colegio; y las haciendas de Llanogrande y Trapiche en Palmira, las haciendas Evigers, Japio, Coconuco y Pandiguando. Desde un principio, los Jesuitas formaron muchas vocaciones para el estado eclesiástico y educación superior para las jóvenes generaciones, escogidas entre las principales familias payanesas y entre ellas, los Arboledas y los Mosqueras.Después de la Expulsión de los Jesuitas, mediante la Pragmática Sanción del 2 de abril de 1767, por la cual el rey Carlos III los desterró de todos los dominios españoles, el Real Colegio Seminario de Popayán estuvo cerrado durante 10 años, hasta que el Gobierno español dispuso que pudiera continuar la Casa de Estudios. El 11 de julio de 1778, la iglesia del Colegio Seminario fue entregada al Dr. Juan Mariano de Grijalba, cura de la iglesia parroquial de Popayán. Por ese mismo tiempo, el Señor Obispo nombró Rector del Colegio Seminario al Dr. José Matías García de la Plaza, quien había servido en Buga la iglesia que era de los Jesuitas. La ciudad de Popayán recibió con mucho júbilo la reapertura del Colegio Seminario y recordó la obra insigne de los Jesuitas en Popayán. Al reiniciar las clases se abrieron los cursos de filosofía, lengua latina, teología dogmática y moral; asimismo ciencias naturales y experimentales.

Se hicieron los concursos para las cátedras de Filosofía, Leyes, Latinidad, Retórica, Derecho Canónico, Sagrada Escritura y otros, cuyos exámenes 
públicos de oposición se hicieron en la Iglesia de la Compañía. Cada uno de los opositores pronunció sobre su tema su oración latina de una hora. La provisión de cátedras salió el 23 de junio de 1779. La cátedra de Filosofía no tuvo aspirantes, por lo cual fue difícil conseguir el catedrático para esta asignatura. El Dr. Joaquín Rodríguez se presentó en abril de 1780, pero después de haber hecho la oposición y haber sido nombrado, renunció al poco tiempo.

En 1781 el Seminario de Popayán tenía problemas de inconformidad de los profesores por la demora en el pago de sus salarios. Además se criticó la falta del curso de Filosofía por la dificultad de encontrar el profesor correspondiente. A mediados del mes de octubre de 1782 hizo oposición a la cátedra de Filosofía el joven antioqueño Dr. José Félix de Restrepo, recién graduado en Jurisprudencia. Le hicieron el examen de oposición, el Señor Rector Plaza y el Dr. Manuel Antonio Tubianez en la casa del Sr. Provisor Dr. Manuel José de Mosquera, en donde sacó puntos por el curso de Goudin. Un día después, en presencia del Señor Gobernador D. Pedro de Becaría y un grupo de profesores, el Dr. José Félix de Restrepo les habló durante una hora, respondiendo durante otra los argumentos de sus replicantes. A todos los dejó completamente satisfechos, por lo cual se hizo acreedor a la Cátedra de Filosofía. El Rector Juan Mariano de Grijalba le certificó sus méritos como catedrático de Filosofía en el Seminario, el $1^{\circ}$ de marzo de 1786:

En cumplimiento de lo prevenido por el decreto antecedente, certifico que hallándose informado el Ilustrísimo señor doctor don Jerónimo Antonio de Obregón y Mena, de buena memoria, Obispo que fue de esta Diócesis, de la literatura y prendas del doctor don José Félix de Restrepo, y movido del celo con que propendía a la instrucción de la juventud en este Real Colegio Seminario, y de acuerdo con el gobierno, lo hizo venir de la Provincia de Antioquia con el fin de que enseñase Filosofia: y que habiendo venido y hecho oposición a la cátedra se le dio en propiedad. En cuya virtud enseñó los tres años dictando lo principal y más útil de la Filosofia escolástica y todas las partes Físico-Matemáticas que expresa con grande aprovechamiento y ventajas de la juventud, estableciendo un estudio tan útil y necesario, cuyos progresos han sido notorios en las funciones públicas y en los exámenes privados de sus discípulos. Certifico igualmente que satisfecho el gobierno del acierto con que desempeñó el curso anterior de Filosofia, le solicitó por mi medio para que continuase la regencia de dicha cátedra en el curso siguiente.... ${ }^{8}$

8 VARGAS SÁEZ, Pedro, C.M. (1945): Historia del Real Colegio Seminario de San Francisco de Asís de Popayán. Academia Colombiana de Historia. Biblioteca de Historia Nacional. Vol. LXXV. Bogotá, Editorial A.B.C. 
La época de oro del Seminario de Popayán fue en los finales del siglo XVIII bajo la rectoría del Dr. Juan Mariano Grijalba, quien estuvo 25 años en su Rectorado; y del educador Dr. José Félix de Restrepo, quien fue un excelso "Maestro" muy querido por sus alumnos y muy respetado por la Sociedad de Popayán. Entre los años 1782 a 1789 dirigió 47 tesis filosóficas, 29 de las cuales se refieren a temas de física y otras a filosofía, siguiendo las ideas de Descartes, Gassendi, Leibnitz y Newton.Su alumno Camilo Torres defendió su tesis en latín el día 22 de enero de 1785 en el Colegio Seminario. El 4 de junio de 1786, el joven Francisco José de Caldas, "el Sabio Caldas", sustentó su tesis de ciencias naturales, bajo la dirección de su Maestro el Dr. Restrepo. Algunos aspectos de su tesis fueron las siguientes:

Primeramente explicase la naturaleza de la luz que consiste en el movimiento de una sustancia fluida, elástica y sumamente movible.

Se demuestra que la luz no es emanación sustancial del sol y se exponen las leyes de la propagación de la luz. $1^{\circ}$ La propagación de la luz es sucesiva; $2^{\circ}$ Se hace en línea recta. $3^{\circ}$ Se hace con movimiento igual; $4^{\circ}$ Disminuye intensivamente a proporción que se aumenta el cuadrado de la distancia.

"Se explica y defiende el ingenioso sistema del abate Noblet sobre la reflexión de la luz, manifestando que no se refleja de lo sólido de las superficies sino de sus poros.

"Se demuestra que la diafanidad o transparencia de los cuerpos proviene de la posición rectilínea de los poros según todas direcciones.

"Se exponen las leyes que sigue la luz en los espejos planos, cóncavos y convexos.

"Se explican las leyes de la refracción de la luz cuando pasan de un medio a otro de diferente densidad y se demuestra que la luz pasando de un medio menos denso a otro más denso padece refracción acercándose a la perpendicular.

"Se explican las hipótesis de Gasendo, de Maygnan y de Newton sobre la causa de la refracción de la luz.

"Se exponen y explican las leyes que sigue la luz en las lentes cóncavas y convexas.

"Por la refracción de la luz se explican los siguientes fenómenos: $1^{\circ}$ Por qué el fondo de un vaso lleno de agua parece más alto de lo que está. $2^{\circ}$ Por qué un bastón metido en el agua parece quebrado. $3^{\circ}$ por qué los cuerpos colocados bajo el agua aparecen más grandes de lo que están, con otros muchos de la misma naturaleza. 
Javier Ocampo López

"Explicase la construcción del ojo, sus túnicas y humores y se demuestran las siguientes proposiciones: $1^{\circ}$ la sensación se hace en la túnica llamada retina. $2^{\circ}$ Las imágenes se pintan en el fondo del ojo situado a la inversa. $3^{\circ}$ El no ver duplicada la imagen con ambos ojos no depende de la concurrencia de los nervios ópticos. $4^{\circ}$ Las cosas que se ven bajo de mayor ángulo insensible no se ven. $5^{\circ}$ las cosas que se ven bajo un mismo e igual ángulo aparecen iguales. $6^{\circ}$ Los puntos de la imagen pintada en el fondo de los ojos por el objeto radiante, aparecen fuera de ellos en aquel punto donde se unen los ejes ópticos.

"Se explican muchos fenómenos pertenecientes a la visión, por ejemplo los siguientes: ¿Por qué con un solo ojo no se puede ver la mitad de una esfera?. ¿Por qué un cuerpo que se mueve rápidamente a grandes distancias de nuestros ojos parece en quietud? ¿Por qué cuando pasamos de un lugar claro a un oscuro y al contrario no vemos el principio de los objetos y poco a poco los vamos percibiendo? ¿Por qué dos paredes paralelas parecen unirse entre sí, si el ojo está colocado en medio de ellas?

"Se examina la célebre cuestión, sobre la naturaleza del alma de las bestias y se demuestran las proposiciones siguientes: $1^{\circ}$ El alma de las bestias es divisible en partes integrales. $2^{\circ} \mathrm{El}$ alma de las bestias no es sustancia espiritual. $3^{\circ}$ Las bestias no pueden conocer, raciocinar, ni sentir si no tienen alma espiritual. $4^{\circ}$ La materia es incapaz de sentir. $5^{\circ}$ Las bestias son puros autómatas o máquinas destituidas de sensación y conocimiento y ejecutan todas sus acciones por puro mecanismo. $6^{\circ}$ la opinión de que los brutos sienten, confunde la naturaleza del espíritu y de la materia y abre puerta al materialismo. $7^{\circ}$ Sólo la preocupación nos hace mirar a las bestias como dotadas de sensación y conocimiento".

En una carta del Sabio Caldas al Sabio Mutis, escrita el 5 de agosto de 1801, le dice lo siguiente: "Por fortuna me tocó un catedrático ilustrado (Dr.José Félix de Restrepo) que detestaba esa jerga escolástica que ha corrompido los más bellos entendimientos; me apliqué bajo su dirección al estudio de la aritmética, geometría, trigonometría, álgebra y fisica experimental, porque nuestro curso de filosofia fue verdaderamente un curso de fisica y de matemáticas. ${ }^{9}$

La Oración de Estudios para el ingreso de la Filosofía en Popayán. En el mes de octubre de 1791, el Maestro José Félix de Restrepo hizo la "Oración de Estudios" en el Real Colegio Seminario de Popayán. Su objetivo fue el elogio de la Filosofía natural, con los estudios de las matemáticas y la física moderna.

9 DE CALDAS, francisco José. "Carta a José Celestino Mutis sobre su educación en el Seminario de Popayán”, en Historia del Real Colegio Seminario de San Francisco de Asís de Popayán, óp. cit. pp. 554, 555, 556.

Rhela. Vol. 14. Año 2010, pp. $9-60$ 
Según sus ideas, el estudio y dominio de la naturaleza física es el objeto de la filosofía natural y lo que comunica grandeza a la criatura humana. Señaló la importancia de las matemáticas, la física y las ciencias naturales y experimentales; destacó los aportes de los clásicos griegos y latinos; las ideas de Descartes, Leibnitz y Newton, y en especial de Cicerón. Sin embargo, expresó en su discurso: "La filosofía que emprendemos no es cartesiana, aristotélica, ni newtoniana. Nosotros no nos postramos de rodillas para venerar como oráculos los caprichos de algún filósofo. La razón y no la autoridad tendrá derecho a decidir nuestras disputas. Tampoco nos detendremos en examinar cuestiones que no tengan verdadera relación con los intereses del hombre y sea preciso olvidar al salir del estudio, como son casi todas las celebradas en la escuela peripatética. La carrera de las ciencias es muy larga y demasiado corta la vida humana, para hacer tan mal uso del tiempo".

Para terminar su "Oración de estudios" en Popayán, dice a sus alumnos como consejos del Maestro:

Procurad ser útiles a vuestras familias, a vuestra patria y a todo el mundo. Este es el sentimiento de Catón: "non sibi sed todo gentium se cretere mundo". Como el pensamiento es lo que nos distingue de las bestias, el buen uso de este talento es lo único que puede elevarnos sobre el resto de los hombres. Gerón, los Dionisios y otros reyes de Siracusa, poseídos de una cierta vanidad y soberbia, juzgándose superiores a los demás hombres, no respetaban ni la dignidad, ni el nacimiento, sino sólo a la sabiduría. Cambises ponía delante de los ojos de su hijo Ciro la obligación de ser sabio para poder ser rey. ${ }^{10}$

En el año 1791 acudían al Seminario de Popayán 232 alumnos, de los cuales asistían 32 a filosofía, 25 a moral, 17 a derecho civil y canónico, 80 a latinidad y 80 a las primeras letras.Su vida profesional y matrimonio. Cuando inició su vida profesional en Popayán, para adquirir la práctica forense, el Dr. José Félix de Restrepo asistió durante dos años al estudio del doctor Manuel Antonio Rubianes, a partir del primero de noviembre de 1782. En el certificado que le expidió el abogado Rubianes, señala que ejerció "todos los autos y puntos de derecho con gran puntualidad”. Con sus experiencias jurídicas, solicitó que se le inscribiera como abogado en las Reales Audiencias de Santa Fe y Quito, que era requisito para ejercer su profesión.

\footnotetext{
${ }^{10}$ DE RESTREPO, José Félix. (1971): “Oración para el ingreso a los estudios de filosofía", pronunciado por el Dr. José Félix de Restrepo en el Real Seminario de San Francisco de Asís de Popayán en octubre de 1791", en Papel Periódico, viernes 16 de diciembre de 1791; Véase también DE RESTREPO, José Félix. (2002): Obras completas. Contextualización y notas por Daniel Herrera Restrepo. Bogotá, Universidad Santo Tomás. Facultad de Filosofía. pp. 413-421.
} 
En agosto de 1786, el Dr. José Félix de Restrepo se presentó en Santa Fe de Bogotá a la Real Audiencia en donde fue examinado en Derecho por el Virrey Presidente, el Regente y los Oidores de la Real Audiencia y Chancillería del Nuevo Reino de Granada. Y también se hallaba presente el fiscal. Después de haber presentado el examen correspondiente y de haber merecido la aprobación se le recibió el juramento de rigor y fue nombrado Abogado de la Real Audiencia de Santafé de Bogotá, el 7 de septiembre de 1786. El 17 de enero de 1787 fue incorporado a la matrícula de abogados de la Real Audiencia de Quito. El 11 de agosto de 1787, el Arzobispo Virrey Antonio Caballero y Góngora lo nombró Juez de Balanza de la Real Casa de la Moneda de Popayán, para reemplazar a don Joaquín de Lemos. En la terna de selección también iban los nombres de Tomás Quijano e Ignacio Carvajal. En el año 1788 fue nombrado Fiscal de la Junta de Temporalidades y de la Real Hacienda; y el 17 de julio fue designado interinamente Asesor General del Gobierno de Popayán.En 1791 fue nombrado asesor general del gobierno de Popayán; asimismo, Alcalde Ordinario de Popayán, Gobernador encargado, Subdelegado general de Rentas y Asesor del Virrey José de Ezpeleta. En el año 1793 fue nombrado Oidor de la Real Audiencia de Quito; y en 1795, fue nombrado Fiscal de la Real Audiencia y Padre General de Menores.

Su matrimonio. El 30 de mayo del año 1788 , el doctor José Félix de Restrepo contrajo matrimonio con Doña Tomasa Sarasty Ante y Valencia, de la alta sociedad payanesa, hija del caballero español don Francisco Ignacio Sarasti y Aibar, de Vizcaya, y de doña María Joaquina Ante Valencia, familiar de don Pedro Agustín de Valencia, primer Conde de la Casa Valencia. Sus hijos fueron León Félix, quien murió en la infancia, María Josefa, Manuel María, Mariano y Cristóbal, quienes nacieron en Popayán. En su vida personal se destacó por ser modesto y afable; era muy versado en Historia y se caracterizaba por recordar hechos del pasado y oportunas citas, pensamientos y proverbios en sus conversaciones. Leía mucho los libros de los clásicos, especialmente las obras de Virgilio, el poeta de la paz romana y de la serenidad clásica; al leerlo con gusto, saboreaba las églogas, que eran de su mayor interés. Su diversión favorita era la caza de liebres y conejos, que hacía los domingos después de oír misa. Cuando iba de cacería llevaba siempre un libro, que leía mientras los perros descubrían la presa. ${ }^{11}$

El recuerdo del Maestro en sus alumnos de Popayán. Sus alumnos lo recordaban como precursor de la Independencia y "Maestro de Heroísmo". En

\footnotetext{
11 Véase la obra del historiador RESTREPO, Carlos. (1970): José Félix de Restrepo. Jurisconsulto, humanista y hombre de Estado. Bogotá, Editorial Nelly.
} 
una carta que le envió el General José Hilario López a Don Manuel Restrepo Sarasti, hijo del Dr. José Félix de Restrepo, le recuerda aspectos muy significativos de la vida del gran Maestro como precursor del movimiento patriota. Refiere el General López que los payaneses tenían una tertulia o escuela democrática en Popayán, la cual presidía Don Mariano Lemos, y en donde intervenía con su sapiencia el Maestro Restrepo. A ella asistían "los Arroyo, los Larraondo, los Hurtado, los Miguel Rodríguez, los Tejada, los Quijanos, los López, los Medina, los Fernández, los Valdéz, los Vallecilla, Lemos, los Arboledas, los Torres, los Mosquera, los Mejía, los Escovar y otras personas distinguidas". En esa escuela democrática se trataban los temas de la libertad y la independencia; las doctrinas políticas y las demostraciones sobre la importancia de defender la causa hispanoamericana. Sobre la participación del Maestro Restrepo en la Guerra de Independencia, su discípulo José Hilario López, recuerda lo siguiente:

Hallábame estudiado el año de 1811 en el Colegio de Popayán, en el cual regentaba la cátedra de Filosofía el Sabio doctor Restrepo; y en el asalto que dio a la ciudad el Ejército realista a las órdenes de don Antonio Tenorio, mandando en la plaza el bizarro Coronel Cabal a la cabeza de un puñado de soldados cinco veces inferiores en número a los enemigos, el doctor Restrepo se constituyó espontáneamente caudillo de algunos estudiantes que le rodearon, y ayudando a la defensa común desde el mismo colegio, fue el primero que disparó su arma contra los asaltadores; y yo, a su ejemplo, hice fuego con la mía, admirando con entusiasmo la sangre fría de mi caudillo, a quien miraba en esos momentos críticos como a un semi-dios. ${ }^{12}$

En sus "Memorias", el General José Hilario López recuerda también el hecho de 1811 cuando el Alférez Real Antonio Tenorio asaltó a Popayán con más de tres mil hombres. Así expresa su recuerdo cuando el Maestro fue el primero en ponerse al frente de sus discípulos en defensa de la ciudad y también el primero en disparar contra los invasores:

Los superiores de mi Colegio y la mayor parte de los alumnos éramos patriotas y armados con algunas pistolas, escopetas y lanzas, y esforzados por el ejemplo del virtuoso y respetable republicano doctor FÉLIX DE RESTREPO, catedrático de filosofia, nos resolvimos a defendernos a todo trance.... Los colegiales llenamos nuestro deber haciendo fuego desde las ventanas, y los realistas fueron al fin rechazados, pero permanecieron sitiando la plaza, para lo cual hicieron una línea de circunvalación. ${ }^{13}$

\footnotetext{
12 HILARIO LÓPEZ, José: "Carta del General José Hilario López a Don Manuel Restrepo Sarasti, hijo del Dr. José Félix de Restrepo", en Vida y escritos del doctor José Félix de Restrepo, op.cit. p. 59.

${ }^{13}$ HILARIO LÓPEZ, José. (1969): Memors. Medellín, Editorial Bedout, Bolsilibros Bedout, vol. 47, pp. 18, 19 - 20
} 


\section{EL Dr. José Félix de Restrepo y la libertad de los esclavos}

El educador Dr. José Félix de Restrepo, "Maestro de la Generación de Independencia", luchó por la libertad de los esclavos en Colombia y por la Reforma Educativa, tanto de primaria en Antioquia, como la secundaria y universitaria a nivel nacional en la Década de los Veinte en el siglo XIX. Su labor educativa en el Seminario de Popayán durante 29 años fue fecunda; se convirtió en el Maestro de la Generación Precursora de la Independencia; introdujo la Ilustración y la educación naturalista y experimental en Popayán. Sus discípulos Camilo Torres, Francisco José de Caldas, Francisco Antonio Zea, Francisco Ulloa, Tomás Cipriano de Mosquera, José Hilario López, José María Obando y otros, fueron dirigentes muy notables de Colombia en el siglo XIX.Ante el triunfo de los realistas en Popayán en el año 1812, el Maestro Dr. José Félix de Restrepo salió huyendo de Popayán con el Sabio Francisco José de Caldas y el doctor Francisco Ulloa.

Al iniciar sus actividades en Antioquia fue nombrado vocal del Cabildo de Medellín y Diputado a la Asamblea Constitucional de Antioquia. Propuso la creación de una cátedra de gramática latina, costeada con fondos municipales; dicha cátedra fue regentada por don Ignacio Escobar. En el año 1813 fue llamado para ocupar la cátedra de FILOSOFÍA en el Colegio Académico que más tarde fue la Universidad de Antioquia, en reemplazo del Profesor Liborio Mejía. Allí fue maestro del médico Dr. Pedro Uribe Restrepo, el prócer Alejandro Vélez Barrientos y los antioqueños Juan María y Cástor Gómez Pastor, Manuel Antonio Franco, Vicente Uribe, Francisco de Paula Benítez y otros.

La formación filosófica, educativa y jurídica del Maestro Dr. José Félix de Restrepo lo llevó a defender con pasión la Libertad absoluta de los esclavos. En el siglo XVIII se divulgaron los derechos naturales e inalienables del individuo; entre ellos, el derecho a la igualdad de todos los seres humanos, la libertad, la propiedad y la seguridad. Todos los hombres tienen derecho a ser libres e iguales y a disfrutar de los derechos naturales e inalienables, entre los cuales figura la libertad, el goce de la vida, la propiedad y la búsqueda de la felicidad. Son los derechos dirigidos a proteger al hombre como miembro de la sociedad. Precisamente para garantizar estos derechos, los hombres establecieron los gobiernos democráticos, de los cuales se derivan los justos poderes concedidos a los pueblos por el libre consentimiento y voluntad general.

En la mentalidad antropocéntrica de los siglos XVIII y XIX, la Libertad y la Igualdad de todos los hombres se convirtieron en las ideas-símbolos del nuevo orden universal. Liber en latín significa "el que no es esclavo"; "liber sui juris", 
que no depende de otro. La Libertad es ese poder inmanente que tienen los hombres y los pueblos para decidir su propio destino; para autodeterminarse por libre decisión; y para definir su futuro, de acuerdo con sus necesidades, intereses y aspiraciones. La igualdad en latín aequalitas, atis, significa, equidad o principio que reconoce a todos los ciudadanos capacidad para los mismos derechos.

En busca de la libertad han luchado los seres esclavos de todos los pueblos; aquellos que han sido sujetados, vendidos y dominados por sus amos. La esclavitud priva a los hombres de su libertad y lleva a que se les considere como una mercancía. En las culturas griega y romana se acostumbró en casos muy especiales dar la libertad a los esclavos. Al liberto se le ponía el gorro frigio, símbolo de la libertad de los esclavos. Por esta libertad lucharon los jesuitas Alonso de Sandoval y su discípulo San Pedro Claver en Cartagena de Indias, el centro negrero del Nuevo Reino de Granada. También los jesuitas Francisco José de Jaca y Epifanio de Borgoña, quienes alborotaron a los negros esclavos en Cartagena, Cuba y otros lugares de América. Para ellos, "la esclavitud es pecado de Judas" y está en contra de la naturaleza racional. El hecho de ser cristiano significa ser libre y defender la igualdad de todos los seres humanos. Ellos son los precursores de los Derechos Humanos en Hispanoamérica y quienes iniciaron el proceso de la abolición de la esclavitud desde el Nuevo Reino de Granada.

Algunos esfuerzos por la liberación de los esclavos se hicieron en la segunda mitad del siglo XVIII. Los esfuerzos de doña Javiera Londoño y de su esposo don Ignacio Castañeda en Rionegro (Antioquia), llevaron a la libertad de sus 120 esclavos en el año 1767. Don Lorenzo Agudelo en Santafé de Antioquia dio libertad a 80 esclavos suyos de la mina de Buenavista. En 1781 el comunero José Antonio Galán proclamó la libertad de los esclavos de la mina de Malpaso, cerca de Mariquita. José Ramón de Posada en Medellín, liberó sus 83 esclavos en 1813; asimismo Francisco Mejía y otros de la región de Antioquia, en donde existían muchos esclavos por la producción del oro en las minas y los trabajos esclavistas en las haciendas y el servicio doméstico.

El ideólogo que más defendió la igualdad de todos los seres y por consiguiente la libertad absoluta de los esclavos en la Nueva Granada, fue el Maestro Dr. José Félix de Restrepo. Tuvo dos momentos de importancia para la defensa de la libertad de los esclavos: en Antioquia en los años 1813 y 1814 en la Dictadura del Gobernador Don Juan del Corral, para quien redactó el Proyecto de Ley sobre la manumisión de los esclavos africanos y sobre los medios de redimir sucesivamente a sus padres, aprobado mediante la Ley del 20 de abril de 1814 . 
Siete años después, el Dr. Restrepo presentó el Proyecto al Congreso de la Gran Colombia reunido en Cúcuta en 1821, el cual fue aprobado, después de grandes e históricos debates.

En el Nuevo Reino de Granada, uno de los ilustrados que más recibió las influencias de los filósofos de la igualdad, la libertad, la justicia social, los derechos humanos y el contrato social, fue el Maestro Dr. José Félix de Restrepo. Fue un gran rousseauniano alrededor de las ideas del pensador ginebrino Juan Jacobo Rousseau, quien proclamó las ideas de contrato social, soberanía popular, voluntad general, igualdad y la libertad de todos los seres humanos. En su estudio "Ideas de Gobierno", el Maestro Restrepo defendió las ideas del Contrato social y la voluntad general. Así expresó Restrepo: "Si queremos un gobierno estable y duradero es indispensable que sea querido, llamado de los pueblos. De lo contrario, en lugar de sostenerlo se empeñarán en destruirlo. Yo estoy firmemente persuadido de la verdad de aquel axioma político: que jamás un Estado se gobierna bien sino es por su propia voluntad..... Se trata de hacer un contrato, el más santo que pueda hacerse entre los hombres: el contrato social...".

Con las ideas de contrato social, voluntad general y soberanía popular, el Maestro José Félix de Restrepo defendió con pasión las ideas de la igualdad y la libertad de los hombres y los pueblos. Con sus defensas se convirtió en el adalid de la Libertad de los Esclavos, no solamente para el Nuevo Reino de Granada, sino para todos los pueblos del mundo. .

La libertad de los esclavos en Antioquia. Para el Maestro Dr. José Félix de Restrepo los principales argumentos para la defensa de la Libertad de los Esclavos y la igualdad de todos los hombres fueron los Derechos del Hombre y la Justicia social. En el preámbulo del Proyecto de Libertad de los Esclavos en Antioquia, sostiene que para establecer los fundamentos sólidos de un orden social y justo, son necesarios los altos principios de la justicia social, el respeto a los fueros de la persona humana y el acatamiento a las supremas normas del Derecho natural. Así defendió la Libertad de los Esclavos en la República de Antioquia en 1814:

Cuando el Ser Supremo pronunció la libertad de los pueblos de América, y la destrucción de sus opresores, no fue desde luego con otro objeto que con el de hacerlos más virtuosos, más justos y más dignos de volver a ejercitar sus derechos primitivos. En vano habrian quedado rotas las cadenas de las presentes y futuras generaciones, si una parte de la humanidad que ha gemido en la servidumbre más abyecta 300 años ha, hubiera de continuar siempre ultrajada y envilecida, para que la otra, elevada por el curso natural 
de los hados a la dignidad de su ser, se apropiase exclusivamente el fruto de nuestra regeneración civil. Tal sería, no obstante, el espectáculo monstruoso que ofrecerían a las naciones del universo nuestras operaciones politicas y lo que atraería sobre nosotros la ira del Cielo, si cuando entonamos himnos a la libertad y celebramos el triunfo conseguido sobre nuestros tiranos, con una contradicción manifiesta, agravásemos las miserias de cierta clase de hombres, sin acordarnos que ellos también están marcados con los mismos derechos que concedió a los demás el Autor de la naturaleza. ${ }^{14}$

Con base en las ideas del Maestro Dr. José Félix de Restrepo, el Dictador Don Juan del Corral envió un mensaje a los Legisladores de la República de Antioquia, en el cual señaló que la libertad se consolidará para siempre cuando desaparezca entre nosotros "hasta la sombra de la esclavitud". Solamente con la justicia social, se consolidará definitivamente la libertad de los pueblos y con ella, "la libertad de los esclavos". En su mensaje, el Dictador señaló los problemas de la esclavitud en el mundo, desde Esparta cuando tuvo en cadenas a los ilotas; las guerras de los esclavos en Sicilia y las crueldades practicadas en la isla de Haití; y los rigores de la esclavitud en la Nueva Granada. En este mensaje agradeció la labor del doctor José Félix de Restrepo “uno de los más virtuosos e ilustrados conciudadanos" 15

La Ley del 20 de abril de 1814 fue aprobada por el Cuerpo Legislativo de Antioquia que constaba de cinco miembros: Pbro. José Miguel de la Calle, Presidente; Antonio Arboleda, Vicepresidente; Pedro Arrubla, José Pardo y José Antonio Benítez. El proyecto llevaba el respaldo de los dos personajes más prestigiados de Antioquia: el filósofo Dr. José Félix de Restrepo, quien fue el ideólogo y el Presidente Dictador Don Juan del Corral, quien fue el ejecutor con el Cuerpo Legislativo de Antioquia.La Ley declaró libres a los nuevos hijos de las esclavas (Libertad de partos) e impuso a los amos la obligación de mantener a los libertados hasta la edad de 16 años, y a éstos la de prestar sus servicios a los amos hasta esa misma edad. Asimismo dispuso que los que tuviesen herederos forzosos, dejaran libres por su testamento la décima parte de sus esclavos, y los que no tuviesen herederos, la cuarta. Estableció también para la manumisión sucesiva una contribución anual de dos pesos por cada esclavo varón y de un peso por cada mujer; prohibió la exportación e importación de esclavos y la separación de sus padres e hijos. La República de Antioquia, que era región

\footnotetext{
${ }^{14}$ DE RESTREPO, José Félix. (1814): “Proyecto de Ley sobre la manumisión de la posteridad de los esclavos africanos y sobre los medios de redimir a sus padres". Rionegro, 20 de febrero de 1814, en Vida y escritos del doctor José Félix de Restrepo, óp, cit, p. 69-73.

15 Véase la obra de POSADA, Eduardo. (1935): La esclavitud en Colombia. Bogotá, Editorial Nelly. Asimismo la Biografía de Don Juan del Corral del historiador CORREA, Ramón. (1918): Manizales, Imprenta Renacimiento, p. 199.
} 
minera y en donde era necesaria la fuerza de los negros africanos, fue la única en la Nueva Granada que aprobó la Libertad de los esclavos; ninguna otra provincia imitó su ejemplo. Recordamos que en Haití se decretó por primera vez la libertad absoluta de los esclavos en el año 1794; Inglaterra abolió la esclavitud en 1833; Francia en 1848; Estados Unidos, después de la Guerra Civil de Norte contra Sur en 1864; España en 1868 y Brasil en 1888, entre otros países.

Esta ley estuvo en vigor hasta la caída de la República en 1816, cuando los españoles de la Reconquista restablecieron la esclavitud; desde entonces se convirtió en el orgullo de los antioqueños en el panorama nacional. Don Juan del Corral murió el día 7 de abril de 1814, trece días antes de la aprobación de la Ley de Libertad de los Esclavos. ${ }^{16}$ En el año 1815 el Dr. José Félix de Restrepo participó en la Convención Constituyente de Antioquia, la cual se reunió en Envigado desde el 13 de junio hasta el 4 de julio. Allí se discutió y revisó la Constitución de Antioquia. Varios artículos de dicha Constitución fueron redactados por los jurisconsultos Félix de Restrepo y José Manuel Restrepo, a cuyo cuidado fue puesta la redacción y formación de la Ley fundamental.

\section{El Maestro Restrepo en los años de la reconquista y del triunfo republicano}

En los años de la Reconquista Española, el Dr.José Félix de Restrepo, quien fue ideólogo de los patriotas en los años pre-revolucionarios y en la Primera República Granadina, tuvo que ocultarse algún tiempo en las regiones del sur del Nuevo Reino de Granada. Ante la llegada de los realistas comandados por Francisco Warleta, se refugió en Buga. En 1816 en nombre del Cabildo de Buga, entabló negociaciones de paz con Juan Sámano, cuya exigencia fue el juramento de fidelidad al monarca. Dictó el acta de fidelidad del Cabildo de Buga y refrendó su actitud con donativos, entre ellos, un caballo bayo para el servicio del Rey y 400 patacones. Se convirtió en un mediador entre la insurrección y la autoridad del monarca, para alcanzar la paz. Esta actitud fue manifestada por algunos patriotas, ante la fuerza dominante de la Reconquista Española, señalando entre ellos al Sabio Francisco José de Caldas y al cura Juan Fernández de Sotomayor, el último Presidente del Congreso de las Provincias Unidas. Se retractaron ante las autoridades españolas, aprovechando el indulto, pero continuaron con fidelidad a sus ideas patriotas.

\footnotetext{
${ }^{16}$ Sobre la Libertad de los esclavos, véase la obra de RESTREPO, Carlos. (1938): Canal La libertad de los esclavos en Colombia" (Leyes de Manumisión). Bogotá, Imprenta Nacional.
}

Rhela. Vol. 14. Año 2010, pp. $9-60$ 
El Dr. José Félix de Restrepo regresó a Medellín en 1817, en donde le correspondió justificar su conducta patriota ante las autoridades españolas, para poder obtener el indulto. En los primeros meses de 1817 respondió el interrogatorio sobre su conducta ante el Gobernador de Antioquia Vicente Sánchez de Lima, quien conociendo su gran experiencia en la docencia, le solicitó que se hiciera cargo de la cátedra de Matemáticas. En el informe que éste rindió al Virrey Montalvo el 6 de febrero de 1817 le dice lo siguiente sobre el Maestro Restrepo:

El en verdad que no ha sido de los corifeos y principales motores de la rebelión, y aunque fue colocado en algunos destinos por los insurgentes, no influyó jamás directamente en el trastorno político de la Provincia ni desmintió nunca la moderación y genio pacífico que le caracteriza. Estoy instruido que algunas veces se le convidó con varios empleos de representación, y no quiso aceptar aquellos que traían consigo el ejercicio de jurisdicción y autoridad pública, prefiriendo la ocupación que le es muy grata de la enseñanza de la juventud a que está dedicado hace muchos años, y a cuyo objeto había yo destinado llamándolo con este fin desde Popayán donde se hallaba. Este sujeto por sus grandes conocimientos, por su honradez y cristiana conducta, así como por su amable carácter y prudencia consumada es el que considero más aparente para el desempeño de la cátedra de Matemáticas... ${ }^{17}$

En el año 1818, aún en el período de la Reconquista Española, el Dr.José Félix de Restrepo desempeñó en Medellín el cargo de Síndico Procurador del Cabildo. De nuevo defendió la Libertad de los esclavos y protestó contra quienes seguían auspiciando el tráfico negrero. La Guerra de Independencia trajo nuevas esperanzas para la abolición de la esclavitud. El Libertador Simón Bolívar, quien recibió ayuda en Haití del Presidente mulato Alejandro Petión, propuso en su programa social, la libertad de los esclavos, una vez culminada la independencia.

\section{El Maestro Restrepo y el triunfo republicano}

En el año 1819, después del triunfo patriota en la Batalla de Boyacá, el nuevo Gobernador y Comandante General de la Provincia de Antioquia, José María Córdova, nombró Director de la Imprenta Oficial al Dr. José Félix de Restrepo, mediante el decreto del 22 de octubre de $1819 .{ }^{18}$

El 6 de diciembre de 1819 por comisión oficial, el Maestro Restrepo entregó al Gobierno republicano el Reglamento para las Escuelas de la Provincia de

\footnotetext{
17 Vicente SÁNCHEZ LIMA. (1817): Carta del Gobernador de Antioquia Don Vicente Sánchez Lima al Virrey Montalvo. Rionegro, 6 de febrero, en Vida y escritos del Dr. José Félix de Restrepo, óp, cit, p. 60-61.

18 CÓRDOVA, José María: "Decreto del 22 de octubre de 1819".
} 
Antioquia. En su Discurso preliminar inició su disertación con un pensamiento del Marqués de Becaría, el cual señala lo siguiente: "El medio más cierto para hacer a un pueblo feliz, es establecer un perfecto método de educación. "En dicho Reglamento señaló la importancia para la sociedad de establecer colegios en donde se instruya a la juventud en el estudio de las ciencias, de las artes y de las bellas letras. Recalcó sobre las cualidades de un buen maestro y sobre las reglas generales para su elección y para la erección de escuelas. Destacó las condiciones de los maestros de primeras letras; en la misma forma, la organización interna para la enseñanza y aprendizaje de la Gramática y Latinidad, la filosofía y la teología. Dio especial importancia a la enseñanza de las matemáticas, pues "son la parte más útil y necesaria de las ciencias, y en ellas están depositados casi todos los conocimientos humanos". Culminó su Reglamento recomendando la creación de las escuelas $\mathrm{y}$ las universidades para la formación en alto nivel de las jóvenes generaciones. ${ }^{19}$

\section{La libertad de los esclavos en el Congreso de Cúcuta}

La Libertad de los Esclavos fue uno de los problemas que más tuvieron discusión y aprobación en el Congreso de Cúcuta en 1821. Su líder más significativo en las polémicas fue el Dr. José Félix de Restrepo, como lo había hecho antes en Antioquia con el Dictador Don Juan del Corral.

.En las votaciones populares que se hicieron en Antioquia, como en las demás provincias de la Gran Colombia, para elegir los diputados para el Congreso de Cúcuta, le correspondió la representación al Dr. José Félix de Restrepo. También fueron elegidos su sobrino Francisco Antonio Zea y los representantes Vicente Borrero, José Manuel Restrepo y Pedro Francisco Carvajal; además, el suplente Don Manuel Santamaría. En esa institución constituyente fue elegido primer Presidente el Dr. José Félix de Restrepo, quien fue acogido por su experiencia, alta formación jurídica y gran espíritu patriota. Sus orientaciones fueron "guía y luz" para este Congreso que dio las bases para el nuevo Estado nacional republicano de Colombia. ${ }^{20}$

El Congreso de Cúcuta de 1821 representa la consolidación de la democracia representativa en la República de Colombia y la juridicidad del nuevo Estado nacional, alrededor de la Constitución de Cúcuta de 1821. Desde un principio, este Congreso fue un modelo de organización y seriedad, con el orden permanente

\footnotetext{
${ }^{19}$ Ibídem, 155-178. p.

${ }^{20}$ UPRIMNY, Leopoldo. (1971): El Pensamiento filosófico y politico del Congreso de Cúcuta. Bogotá, Imprenta Patriótica del Instituto Caro y Cuervo, p 114-153. Véase la obra del historiador BUSHNELL, David. (1966): Régimen de Santander en la Gran Colombia. Bogotá, Editorial Tercer Mundo.
} 
del reglamento interno y el trabajo por comisiones, las cuales fueron cuatro: Constitución y leyes, poderes y peticiones, hacienda y asuntos militares. Tanto los proyectos de constitución presentados, como las leyes, tuvieron exposición de motivos y amplios debates en las sesiones, en los cuales se manifestó el respeto a la libertad de expresión y la tolerancia en las opiniones. Se consolidó la idea del encauzamiento nacional hacia la meta de un Estado de derecho regido por la Constitución y las Leyes y dentro de una Democracia republicana.

La labor del Congreso de Cúcuta se realizó en un período de cinco meses y ocho días, desde el 6 de mayo hasta el 14 de octubre de 1821. Fueron 201 sesiones plenarias, de las cuales se realizaron 140 ordinarias en las horas de la mañana y 61 extraordinarias en la tarde y la noche. El primer presidente del Congreso fue el Dr. José Félix de Restrepo, el gran ideólogo de la Libertad de los Esclavos; y como Vicepresidente fue nombrado el venezolano Dr. Fernando de Peñalver. Otros Presidentes del Congreso fueron los diputados José Ignacio de Márquez (3 veces), Alejandro Osorio (2 veces), Miguel Peña (2 veces), Fernando de Peñalver, José Manuel Restrepo y Vicente Azuero.

En el Congreso de Cúcuta, el Dr. José Félix de Restrepo presentó el Proyecto sobre la LIBERTAD DE LOS ESCLAVOS, que antes lo había aprobado la Provincia de Antioquia en el año 1814. Aumentó dos artículos para mayor claridad y lo presentó al Congreso el 28 de mayo de 1821. Un mes después, bajo la Presidencia del Dr. José Ignacio de Márquez, se discutió el memorable proyecto. Así expresa el Acta:

Leído el proyecto de Ley sobre manumisión de esclavos, tomó la palabra el señor Félix Restrepo, y en un discurso elocuente y enérgico, pintó con los colores más vivos los males de toda especie que sufren los esclavos, las razones urgentes de justicia que hay para darles su libertad y el bien que resultaría de ello a la República, por lo cual adujo textos de la Sagrada Escritura, principios elementales de la ciencia política y de moral. Después descendió a explanar el proyecto sometido al Congreso, y a manifestar la exactitud, justicia y tino de que se halla adornado, pidiendo en conclusión que Vuestra Majestad cumpla el voto de los buenos, llene los deseos de los infelices y satisfaga a la expectación del mundo, que contempla sus operaciones. ${ }^{21}$

En el Discurso sobre la manumisión de los esclavos, que pronunció en el Congreso de Colombia reunido en la Villa del Rosario de Cúcuta, el cual fue

\footnotetext{
21 Congreso Constituyente de Cúcuta. "Acta del 28 de mayo de 1821 en la cual se presentó el proyecto sobre manumisión de los esclavos", en Congreso de Cúcuta. 1821. Libro de Actas. Publicación del Banco de la República. Bogotá, Talleres Gráficos del Banco de la República, 1971, pp. 78-81.
} 
publicado en la Imprenta del Estado en el año 1822, presentó sus ideas sobre la igualdad de los hombres y la libertad de los esclavos. Habló sobre sus experiencias en la Nueva Granada en relación con los amos y negros esclavos. Así dijo en su discurso memorable:

"Yo he observado viajando por algunas Provincias el trato que se les da en minas y haciendas. Mientras que el amo en un lecho delicioso desfruta las dulzuras del sueño, el esclavo está en pie para sacar el oro, o trabajar el azúcar. La primera luz de la aurora viene a advertir a estos miserables que sólo han nacido para el trabajo. Este dura todo el día y parte de la noche, si no se ha completado la tarea señalada por el amo o mayordomo.... Los esclavos nada tienen por propio: sólo deben vivir para sus amos, a ellos deben sacrificar sus potencias y sentidos, y después han de decir como los Apóstoles, aunque por un motivo muy diferente, "hemos sido siervos útiles". Al fin mueren sin haber gustado placer alguno de cuantos la naturaleza concedió a los hombres, y sin dejar a sus hijos otra herencia que la necesidad de trabajar para ingratos. Felices si con la muerte acabarán sus penas, y si pudieran llevar consigo al sepulcro toda su posteridad."

Según sus ideas: la esclavitud es directamente contraria al derecho de la naturaleza, al espíritu del evangelio, a la seguridad y permanencia de la República, a las buenas costumbres y a la justicia social. La independencia de Colombia y de América no debe ser para una sola clase de hombres y familias, sino para todos los hombres sin distingos de razas ni riquezas. Los nuevos gobiernos deben dirigir sus medidas para todos, buscando la común felicidad de sus habitantes.

En su intervención señaló las crueldades de la trata de negros esclavos, desde cuando son cazados en África como animales monteses y luego puestos en el mercado "como se hace con una manada de cerdos, encerrados en un corral, manoseados y registrados por los compradores. La libertad que, según la expresión de un poeta, vale más que todo el oro del mundo, se compra alli por unos dijes de bajo precio, y tal vez por una botella de aguardiente". Lo más sensible, dice el Maestro Restrepo es que los pueblos que sostienen con más ardor la esclavitud, son los cristianos. Los africanos cuentan que su mayor desgracia fue la llegada de los europeos a aquellas tierras; y según ellos, los cristianos introdujeron el tráfico de esclavos y con éste, la espada, el cañón, la pólvora y las balas. Por ello, los africanos han escogido más el mahometanismo que el cristianismo, pues según sus ideas, "los cristianos son una raza de paganos, ignorantes y temibles".

Rhela. Vol. 14. Año 2010, pp. 9 - 60 
Los esclavos sufren la desolación y la miseria cuando son alejados de sus tierras y son trasladados a los lugares de América en donde son sacrificados para el trabajo forzado. Los esclavos son mirados como unos animales indómitos, que es un placer domeñar con el castigo. "Los infelices se ven forzados a sacrificar su sanidad, su fuerza, su voluntad, en fin, todas sus facultades, a unos amos que no los miran con la mitad de este sentimiento afectuoso, que tienen para con sus perros, o para con sus caballos". Y así continúa en su Discurso el Dr. José Félix de Restrepo:

¿Pero qué delito es éste por el que han merecido los hombres una pena tan dura, cuyo reato pasa de generación en generación, y que no se perdona ni en el presente ni en el futuro siglo? ¿Cuáles son los títulos por donde la mitad del género humano se ha apoderado de la otra mitad? ¿En qué razones se funda la sociedad leonina de amos que mandan y gozan, de esclavos que trabajan y sufren? La codicia encuentra muchas. La virtud y la justicia no hallan otras que las que tiene un salteador que después de haber despojado al caminante de su dinero, reclama la protección de las leyes para mantenerse en la posesión de lo que ha usurpado. ${ }^{22}$

El Dr.José Félix de Restrepo recalcó que la esclavitud no es justa y es opresora de la humanidad. Por ello fue insistente ante el Congreso de Cúcuta, cuando expresó: "Si la independencia de España nos ha de costar una sola injusticia; si es necesario continuar la opresión de la humanidad para sostener la República, perezca ésta, no haya oro, seamos esclavos de los españoles, pero seamos virtuosos. "Según sus ideas, la esclavitud es directamente contraria al derecho de la naturaleza, al espíritu del evangelio, a la seguridad y permanencia de la República, a las buenas costumbres, a la población, al aumento de la agricultura, minería y todo género de industria. Sólo resta hallar los medios de conseguir la libertad. Si se oye el interés es absolutamente imposible, si se consulta a la justicia, nada es más fácil.

El Maestro José Félix de Restrepo criticó a quienes afirman que los negros están dominados por todos los vicios; que son perezosos, embusteros, ladrones. "Así hablan los Apóstoles de la tiranía". Todo lo contrario: "Según el testimonio de los viajeros, los negros son capaces de la más completa civilización; tienen inclinación por la música y las artes; poseen virtudes morales; son compasivos, hospitalarios, y en la presente transformación política, han dado ejemplos de generosidad heroica. La fidelidad con que guardan un depósito es inviolable. ”Así culmina su Discurso de la Esclavitud

\footnotetext{
22 FÉLIX DE RESTREPO, José. (1821): "Discurso sobre la manumisión de esclavos, pronunciado en el soberano Congreso de Colombia reunido en la Villa del Rosario de Cúcuta en el año 1821."
} 
el Dr. Restrepo: "Si el soberano Congreso decreta la abolición de la esclavitud en Colombia y lava esta mancha de la humanidad y de la religión, restituyendo a sus hijos los sagrados derechos de la naturaleza, podrá decir con más fundamento y menos jactancia que César: "hice cosas demasiadamente grandes".

Una vez leído el proyecto de Ley sobre manumisión de los esclavos y de haber escuchado el discurso elocuente y enérgico del Dr. José Félix de Restrepo sobre la esclavitud y las razones de justicia social para su abolición, varios diputados intervinieron para apoyar la ley propuesta. Algunos como Fernández de Soto, Pereira, Pedro Carvajal, Fernando Gómez, Bautista Estévez y otros, con inmensa emoción, declararon libres a sus propios esclavos. El Presidente del Congreso de Cúcuta, Dr.José Ignacio de Márquez, una vez aprobado el proyecto de ley por los diputados, declaró oficialmente la Ley del 19 de julio de 1821, conocida en la Historia como la Ley de manumisión de los esclavos en Colombia. Se aprobó la Ley sobre la libertad de partos, la manumisión y abolición del tráfico de esclavos. Cuando se aprobó esta Ley era Presidente del Congreso de Cúcuta don José Manuel Restrepo, y como Secretario Don Francisco Soto. La sancionó el doctor José María del Castillo y Rada, Vicepresidente de la República encargado del Poder Ejecutivo, y el Ministro del Interior, don Diego Bautista Urbaneja.

El artículo $1^{\circ}$ de la ley de manumisión de los esclavos señala lo siguiente: "Los hijos de las esclavas que nazcan desde el día de la sanción de la ley serán libres, y como tales se inscribirán sus nombres en los registros civicos de las municipalidades y libros parroquiales". Ellos serán libres, pero deberán permanecer bajo la tutela de los amos de sus madres hasta la edad de 18 años. Durante ese tiempo de tutela, debían educarse y adquirir hábitos para el trabajo $\mathrm{y}$ otras formas para ganarse la vida.

La Ley sobre la Libertad de los esclavos creó las Juntas de Manumisión, que debían, en un día del año, previamente señalado, manumitir a los esclavos cuyas condiciones de conducta los hicieran más merecedores de este beneficio. La Ley prohibió absolutamente la venta de esclavos para fuera del territorio de Colombia, lo mismo que su extracción con el propio objeto. Se prohibió la introducción de esclavos en el territorio de Colombia, bajo la pena de que por el mismo hecho quedaran libres. El que acredite haber manumitido diez esclavos, que no sean de aquellos que por su avanzada edad o enfermedades no puedan subsistir por sí, será honrado con un escudo de oro que tendrá esta inscripción "Ciudadano benemérito de la República y amigo de la humanidad". La Ley señaló fondos económicos para la manumisión de los esclavos. En 
cada uno de los Departamentos capitulares se erigirá una Junta con el título de amigos de la Humanidad, la cual se interesará por la manumisión de los esclavos, que se realizará anualmente el primer día de Pascua de Resurrección. Se libertará el número de ellos a que alcance el fondo recaudado.

El artículo $18^{\circ}$ señala: "Los esclavos que se vayan libertando se aplicarán a los destinos en que puedan ser más útiles a la sociedad, teniéndose presente que nada será más ventajoso a ésta como dedicarlos a la labor de las tierras incultas, principalmente las de caminos reales, de las que se les dará en plena propiedad una porción que alcancen a cultivar, sin que obste para esto el registro o composición que hayan hecho de dichas tierras algunos propietarios, pues por el mismo hecho de tenerlas abandonadas han perdido el derecho a ellas." 23

La Ley de manumisión de los esclavos que se aprobó en el Congreso de Cúcuta de 1821 fue tímida y no tuvo vigencia total. No señaló lineamientos efectivos para la abolición de la esclavitud. Los esclavistas fueron sus enemigos, especialmente en la región del Cauca, que se opusieron a su ejecución definitiva. Esta Ley no determinó la inmediata liberación de esclavos, pues los mecanismos que fueron montados para comprar su emancipación no funcionaron. En algunas provincias de Venezuela los dineros que fueron recogidos para la manumisión fueron malgastados. Algunos casos de manumisión se presentaron esporádicamente y fueron señalados con publicidad favorable en "La Gaceta de Colombia". En general esta Ley de manumisión no tuvo éxito en la Gran Colombia.

Mediante la Ley 28 de 1843 se hizo represión a los movimientos sediciosos de los esclavos; e inclusive esa misma ley permitió la venta de esclavos por fuera de la Nueva Granada. Contra esta Ley se expidió la Ley del 28 de abril de 1847, mediante la cual se prohibió la importación y exportación de los esclavos en la Nueva Granada.

La abolición de la esclavitud en forma definitiva, la culminó en el año 1851, el Presidente José Hilario López, un discípulo del Dr. José Félix de Restrepo en Popayán. El Presidente López sancionó la Ley del 21 de mayo de 1851 que declaró libres en forma absoluta a todos los esclavos en la Nueva Granada. Los ponentes defensores de la Abolición de la esclavitud fueron los congresistas Lorenzo María Lleras, Manuel María Mallarino, Alfonso Acevedo y otros.

${ }^{23}$ Ibídem, p 76-81. 
Esta Ley dispuso que a partir del $1^{\circ}$ de enero de 1852 fueran libres todos los esclavos que existían en la República de la Nueva Granada. En consecuencia, desde esa fecha todos los que eran esclavos "gozarán de los mismos derechos y tendrán las mismas obligaciones que la Constitución y las Leyes garantizan e imponen a los demás granadinos". En el artículo cuarto de la Ley de Abolición se estableció que "son libres de hecho todos los esclavos procedentes de otras naciones que se refugien en el territorio de la Nueva Granada, y las autoridades locales tendrán el deber de protegerlos y auxiliarlos por todos los medios que estén en la esfera de sus facultades". Así culminó la lucha del Maestro Dr. José Félix de Restrepo por la abolición de la esclavitud en la Nueva Granada, la cual inició en Antioquia en 1814, tuvo su plenitud en el Congreso de Cúcuta con la Ley de Manumisión y la culminó en 1851 su discípulo en Popayán, el Presidente José Hilario López., con la abolición definitiva de la esclavitud.

La cátedra de Filosofia en el Colegio de San Bartolomé: El Dr. José Félix de Restrepo continuó en Santafé de Bogotá distinguiéndose en la cátedra de Filosofía en el Colegio de San Bartolomé, la cual abrió con gran pompa en su "Oración de inauguración" en al año 1822. Una vez terminada la cátedra hizo también su "Discurso de clausura del curso de Filosofía en el Colegio de San Bartolomé", el cual fue publicado en la Imprenta de la República en el año 1825. En esos años fue Ministro y Presidente de la Alta Corte de Justicia, Secretario del Interior y Relaciones Exteriores.

\section{La educación elemental en las ideas del Maestro José Félix de Restrepo}

El Maestro Dr. José Félix de Restrepo fue un educador de grandes méritos, desde sus primeras clases de Filosofía que inició en 1778, cuando estaba terminando su carrera de Derecho Civil en el Real Colegio de San Bartolomé; y durante sus 29 años de labor docente en el Real Colegio Seminario de Popayán. Se convirtió en el gran "reformador de la educación en los orígenes de Colombia. En Antioquia hizo la Reforma de la Educación Primaria, con la elaboración del Reglamento para las Escuelas de la Provincia de Antioquia", el cual fue aprobado por la Asamblea el 6 de diciembre de 1819.Su participación en la reforma educativa grancolombiana fue muy importante en la organización de la educación pública y oficial, alrededor del pensamiento educativo y la acción del Vicepresidente Francisco de Paula Santander en la Gran Colombia. Y en especial, cuando como Director de Estudios hizo la primera Reforma Universitaria en la Gran Colombia, con la cual se creó la Universidad Central, que es actualmente la Universidad Nacional; las Universidades Centrales de Caracas y Quito; y la 
Universidad del Cauca en Popayán, la Universidad de Boyacá en Tunja y la Universidad del Magdalena y el Istmo en Cartagena de Indias.El Dr. José Félix de Restrepo fue el organizador y primer Presidente de la Academia Nacional, que es la predecesora de las actuales Academias de Colombia. Se convirtió en el educador y maestro de las generaciones colombianas que hicieron la Independencia y organizaron las instituciones político-administrativas de la Gran Colombia, con el modelo de un Estado Nacional democrático y republicano.En el Reglamento para las Escuelas de la Provincia de Antioquia en 1819 y en su Discurso de Clausura del Curso de Filosofía en el Colegio de San Bartolomé expuso sus ideas sobre la importancia de la educación en la sociedad. Según sus ideas, nada hay más importante al bien de la sociedad como el establecimiento de colegios y cuerpos literarios, donde se instruya a la juventud en el estudio de las ciencias, las artes y las bellas letras. ¿Y por qué es importante la educación para la formación de la juventud? Así expresó en su Discurso:

\begin{abstract}
Son los jóvenes la parte más preciosa del género humano, y pueden compararse a unas plantas tiernas en que están encerradas las semillas del heroísmo y de la virtud que fomentadas con el riego de la enseñanza, deben algún día producir frutos abundantes en beneficio de la religión y de la patria. Todos los padres de familia, que estiman a sus hijos con un amor sólido y juicioso, están persuadidos de que no pueden hacerles mayor beneficio, que procurarles la perfección del espíritu con el estudio de las ciencias: ellos depositan gustosos esas tiernas prendas de su cariño en los colegios con el mismo designio con que el labrador encomienda el fértil grano a la tierra en la esperanza de abundantes frutos. ${ }^{24}$
\end{abstract}

El Maestro José Félix de Restrepo señala que la Historia no ha olvidado manifestar los cuidados y desvelos que todas las naciones civilizadas han tenido en instruir la juventud. Ellas estaban bien persuadidas de que para tener ciudadanos amantes de la equidad y de la justicia, magistrados que velasen por la seguridad de la patria, y soldados que la defendiesen, era preciso formarlos en el estudio de las letras. Y el maestro da especial importancia a la sabiduría. Así expresa:

La sabiduría es la base y fundamento principal del gobierno de los Estados. Se trata de formar los pactos sociales de los pueblos, de arreglar su conducta, de fijar sus límites, de establecer la paz o declarar la guerra, de promover el comercio, de fomentar la agricultura, de decidir sobre la vida, honor o interés de los particulares, la sabiduría es consultada, y su dictamen dirige todas las operaciones. En la cabaña humilde del pastor no es menos respetable su autoridad que en el supremo consejo de la nación. Hasta la gloria militar, que parece no tener cosa alguna común con las letras, está

\footnotetext{
${ }^{24}$ Ibídem, p. 187.
}

${ }^{25}$ Ibídem, p. 188. 
dependiente de sus preceptos. Las grandes empresas no sólo necesitan el valor del corazón y la fuerza del brazo, sino también la eficacia del raciocinio y la penetración del discurso. ${ }^{25}$

En la Historia de las Antiguas Civilizaciones - dice el Dr. José Félix de Restrepo - los grandes Maestros fueron los pilares de la sociedad. No se entienden las conquistas de Alejandro Magno en Grecia, sin la grandeza del filósofo Aristóteles, quien con sus observaciones facilitó el concurso de sus empresas. Sin la pluma de Homero el nombre de Aquiles tal vez no habría llegado hasta nosotros. El mismo Alejandro lloró al ver el sepulcro de Aquiles, considerándose infeliz en no encontrar otro Homero que celebrase sus acciones. Filipo, padre de Alejandro, se gloriaba más de haber dado a su hijo un maestro sabio, que de haber conquistado la Grecia y muchas veces se vio obligado a confesar que había sido mayor estorbo a sus victorias la elocuencia sola de Demóstenes, que las armas de todos los atenienses. Escipión, Pompeyo y Julio César protegieron las ciencias como necesarias a sus empresas militares. César nos recuerda que debió más a su pluma que a su espada, y que en medio de los combates jamás olvidó el cuidado de las estrellas. Las Repúblicas más poderosas del universo, Grecia y Roma, no llegaron al mayor grado de esplendor y gloria, sino cuando cultivaron las ciencias. Lo anterior lleva a concluir que "sea que consultemos la historia de los siglos pasados o que volvamos la vista a los presentes, quedaremos convencidos de la verdad de esta máxima importante: "La Nación sabia está destinada a mandar, y la ignorante a obedecer."26

El Maestro Restrepo en sus escritos alaba al Vicepresidente Francisco de Paula Santander por el fomento de la educación y por la creación de los colegios y numerosas escuelas en todos los pueblos de Colombia, pues "no hay día en que en algunos de sus puntos no se levanten nuevos altares a Minerva". (26) Restrepo felicitó a la República de Colombia, "nacida como el Fénix, de las cenizas del despotismo español". Felicitó al Libertador, quien "rodeado de amarguras, riesgos y dificultades sinnúmero, concebisteis y llevasteis a cabo la grande obra de arrancar vuestra patria a la tiranía española". Al Vicepresidente Santander, quien consolidó la majestad de las leyes y el imperio de la libertad.

EL Reglamento para las Escuelas de la Provincia de Antioquia Fue formado por orden del gobierno republicano, en diciembre del año 1819 y redactado por el Maestro Dr. José Félix de Restrepo Se dio importancia a la educación para el progreso de los pueblos y como el único camino para hacerlos felices. Las

${ }^{26}$ Ibídem, p. 188.

Rhela. Vol. 14. Año 2010, pp. 9 - 60 
prevenciones generales, inicialmente las ofrece especialmente para los maestros. El maestro debe tener ánimo e inclinaciones de padre para con sus discípulos. En consecuencia debe tratar a sus discípulos con afabilidad, dulzura y amistad, sin declinar a una familiaridad indecente, mirando siempre como su principal obligación el adelanto y progreso de aquellos niños que sus padres y la Patria le han confiado. Procurará en sus discursos y ejemplo comunicarles aquella especie de dignidad y rectitud que debe durar el resto de su vida; inspirándoles en todas ocasiones reconocimiento al Creador, respeto a sus semejantes, amor a la virtud y aborrecimiento al vicio.

El Maestro debe transmitir a sus alumnos el deseo de la sabiduría y la estimación y amor a las ciencias. Estudiará el genio y carácter de los niños para ponerse en estado de gobernarlos bien; unos son conducidos por la dulzura; otros por el temor; a éstos animan las alabanzas, a aquellos los hacen cobardes y abandonados. Debe acostumbrar a los alumnos a la urbanidad del buen trato y amabilidad con los semejantes; evitar la terquedad y el espíritu de contradicción y de disputa; asimismo, sacrificar algo de sus propios derechos por la conservación de la paz.

El Maestro debe infundir respeto, pero con tranquilidad y moderación, no permitiendo el tono áspero y ofensivo. Que su modo de enseñar sea sencillo y paciente; que evite la demasiada severidad o la excesiva indulgencia. Evitará el castigo de azotes o de palmetas, castigando a los niños con pasión y cólera. Las reprensiones y castigos no han de ser ni demasiado largos, ni demasiado frecuentes, de modo que quiten a los niños la esperanza de poder enmendarse. Procurará elevar el espíritu de los niños al amor de la sólida gloria y virtudes religiosas y sociales, apartándolos de la avaricia, de la vanidad y de la ambición. El lujo es pernicioso en la sociedad, por lo cual, los maestros deben acostumbrar a los jóvenes a la modestia en el vestido.

En cada escuela habrá un director, los maestros y los pasantes que les ayudarán en sus actividades didácticas. La ocupación de los maestros será de ocho y media hasta las once de la mañana y desde las tres de la tarde hasta las cinco. Los asuetos serán todos los días de fiesta entera, los de precepto por la tarde, y los sábados, en que también habrá estudio, si hubiese habido en la semana algún día festivo o de precepto. Los niños que sean absolutamente desaplicados, o del todo ineptos, serán despedidos de las aulas en virtud del examen anual. Dice el Dr. Restrepo que este es un punto de mucho interés. Los padres desengañados destinarán sus hijos a otra ocupación útil: la República literaria quedará purgada

${ }^{27}$ Ibídem, p. 188, 189. 
de miembros inútiles, y el Estado eclesiástico recobrará su esplendor por medio de sujetos que unan la probidad a la sabiduría. ${ }^{27}$ En el Reglamento para las Escuelas de Antioquia se establecieron las reglas generales para la elección de maestros y la erección de escuelas. La elección de los maestros será por oposición con examen público ante una Comisión del Cabildo, después del cual recibirá el nombramiento oficial por parte del gobierno. Las escuelas tendrán su edificio en el centro de cada lugar, o en la parte más inmediata; "ha de ser saludable y ventilada y debe contener un patio y huerta de regular capacidad. Estos edificios serán asignados por los Cabildos de los fondos de propios"..

Los maestros de primeras letras son los que ponen los cimientos de la ilustración. Ellos deben poner mucho cuidado en que los niños aprendan a leer y escribir correctamente. Una buena letra se distingue por la limpieza, unión y sobre todo la claridad. Los principios de religión serán aprendidos por el Catecismo de Fleuri o de Pouget; estudiarán la Gramática y Ortografía Castellana de la Academia Española. Al tiempo de leer y escribir les irá advirtiendo el maestro los defectos de ortografía para que los enmienden, recordándoles las respectivas reglas. Para leer principiarán por la cartilla y continuarán con los libros. En la clase de escribir se comenzará por la formación de letras grandes y uniformes entre sí.

La primera disposición del maestro en su escuela será la de formar un libro en que vaya asentado los nombres de los niños, que se le presenten. La partida expresará la fecha, la edad, padres y estado de enseñanza que tienen. Después formará otras tantas listas, como clases en que están divididos, que para el debido orden y más fácil método han de ser cuatro: la de leer, la de escribir, Aritmética y Doctrina, y últimamente la Geometría. A cada clase se le señalará un censor, quien ayudará a instruir a los alumnos cuando el maestro se aleje de los unos para aplicar su atención a los otros.

Cuando los alumnos estén instruidos en las primeras letras, pasarán a la escuela de latinidad, comenzando por aprender las declinaciones, conjugaciones y reglas ordinarias de la sintaxis. La enseñanza se hará por la Gramática de Nebrija u Hornero. Los alumnos leerán los autores antiguos y modernos, tanto poetas como oradores e historiadores, tales como Virgilio, Horacio, Ovidio, Cicerón, Quinto Curcio, Tito Livio, etc. El Maestro irá escogiendo los pasajes más selectos de las obras seleccionadas, haciendo que aprendan algunos a la letra, para que ejerciten la memoria y la llenen de expresiones y frases elocuentes, que adornen su estilo, y perfeccionen la elocuencia natural; advirtiendo que a Virgilio debe leérsele casi todo; y de Cicerón no pueden omitirse Oraciones selectas, el Tratado del Orador y los Diálogos de la vejez y de la amistad. Lo 
importante no deben ser las normas gramaticales sino la lectura de los buenos autores. Al interpretarlos hará conocer a los niños en qué consiste la perfección y belleza del estilo, advirtiéndoles la diferencia del humilde, mediano y sublime, bajo y elevado, pedante y majestuoso. Más que las reglas independientes, lo importante es la lectura, con la aplicación de estas reglas y el análisis literario. Teniendo los niños algún conocimiento del latín, podrán realizar algunas composiciones cortas, las cuales deben contener algún pasaje de historia o alguna verdad de la religión. Lo importante son los ejercicios, los cuales sirven para poner en práctica las reglas que han explicado de palabra. El maestro tendrá cuidado de hacerles notar la construcción y armonía de las diferentes partes del discurso, la propiedad de las palabras, la elegancia del estilo, el uso de las partículas y la rectitud y solidez de las máximas.

Para facilitar y hacer más familiar la inteligencia de la lengua latina, el maestro obligará a los niños a hablar un rato en latín sobre algún punto de historia o de moral, tomado de algún pasaje de los autores que hayan explicado. Los alumnos aprenderán de memoria los pasajes más selectos de los poetas, oradores e historiadores, para que conserven en el depósito de su memoria lo más precioso del genio y del talento. No olvidará la poesía latina, enseñándoles las reglas de sus diferentes especies de metros, la naturaleza, perfecciones y defectos del poema épico y dramático, la comedia y la tragedia, los idilios, sátiras, odas, epigramas, elegías, etc. Ovidio, Horacio, Marcial, Juvenal y principalmente Virgilio, nos ofrecen excelentes modelos de uno y otro.

Cuando ya los jóvenes tengan alguna facilidad para traducir, y estén instruidos en las reglas de la sintaxis, comenzará el estudio de la retórica, y ejercicio de lo que se llama elocuencia. Los exámenes de los alumnos serán públicos; unos estudiantes hablarán de la poesía, otros de la retórica y la elocuencia; y otros de las declinaciones de nombres y conjugaciones de verbos, pretéritos, partes de la oración, etc.

Los estudios de Filosofía serán de tres años. El primero comenzará por la lógica; también se ocuparán los alumnos en los estudios de Aritmética, Geometría, Trigonometría, Álgebra. El segundo se destinará a la física y el restante a la metafísica y filosofía moral; se preferirá las ciencias prácticas y útiles. Otro estudio que se tendrá en cuenta en las Escuelas de la Provincia de Antioquia será el de Teología, alrededor de los Evangelios, los textos de Melchor Cano, los hechos apostólicos, las cartas de San Pablo, las de Santiago y San Judas, continuando la lectura diaria de los capítulos del Antiguo Testamento.

El Maestro Dr. José Félix de Restrepo recomendó erigir en cada uno de los cantones del Estado una escuela de niñas, en que se enseñe el catecismo, a 
leer, escribir y contar medianamente, y también los oficios domésticos, que tanto influyen en la tranquilidad de las familias. Recomendó la conformación de una Escuela de medicina, química y anatomía, reunidas bajo un solo maestro.

Sobre las Matemáticas, dijo el Dr.José Félix de Restrepo:

La aritmética en todas sus partes principales es uno de los ramos más importantes en la escuela de primeras letras. El maestro tendrá un cuidado particular en que los niños la aprendan, como también los primeros elementos de la Geometría. ${ }^{28}$

Al culminar el Reglamento para las Escuelas de Antioquia, dice en el último párrafo su pensamiento sobre la importancia de las matemáticas. Así expresa: "Sería de suma importancia que hubiese una cátedra destinada particularmente a enseñar a fondo las MATEMÁTICAS. Su estudio debería durar dos años, y en este caso el resto de Filosofía quedaría reducido a uno. Las Matemáticas son la parte más útil y necesaria de las ciencias, y en ellas están depositadas casi todos los conocimientos humanos". José Félix de Restrepo. $^{29}$

De acuerdo con su proyecto de Reglamento, los exámenes de los escolares deben ser públicos a fines de noviembre o a principios de diciembre, con la asistencia del Cabildo, maestros de gramática, filosofía, etc. y de algunos vecinos escogidos para el efecto. El maestro señalará la materia sobre lo que cada uno deba ser examinado, con el convite que pase a los examinadores, dividiendo las materias por clases. Se dará gran solemnidad al acto, para que excite la emulación, y haga relucir el mérito de los de mayor talento y aplicación.

De acuerdo con el concepto del Dr. José Félix de Restrepo, la Nueva Granada no tiene los maestros capacitados para ejecutar en toda su plenitud el Reglamento para las escuelas de Antioquia, como se ha propuesto. Señala que los maestros que están encargados de educar la juventud no han sido formados para ello, "juzgo sean dignos de alabanza por lo que hacen, y que no merezcan reprensión por lo que dejan de hacer". El Maestro Restrepo recomienda con urgencia la creación de los estudios superiores en una Universidad. Así expresa:

Tres siglos han corrido desde el descubrimiento de las Américas, y no tenemos en la Nueva Granada, y quizá en la América toda, una sola UNIVERSIDAD bien establecida; aun las de Lima y Méjico, según el testimonio de la Enciclopedia metódica, no merecen este nombre. En toda la Provincia de

\footnotetext{
28 Ibídem, p. 189.

${ }^{29}$ Ibídem, p. 162.

${ }^{30}$ Ibídem, p. 166.
}

Rhela. Vol. 14. Año 2010, pp. $9-60$ 
Antioquia, y en la mayor parte de los vecinos acomodados, y la índole noble de sus habitantes, produzcan dentro de poco hombres capaces de cualquiera enseñanza; y en el Nuevo Reyno se conocen algunos, que se han formado por sí mismos, a despecho de la política y de la falta de libros. ${ }^{30}$

En su ideario humanístico, LA EDUCACIÓN debe ser un todo coherente desde la elemental hasta la educación superior, en la Universidad. Por ello encuentra la necesidad de realizar una reforma profunda en la educación primaria, como la planteó para las Escuelas de la Provincia de Antioquia y la urgente necesidad de crear LA UNIVERSIDAD PUBLICA para la formación de los dirigentes de la Gran Colombia. Ello señala su vinculación con el Gobierno republicano y el nombramiento que se le hizo en 1826 como Director General de Instrucción Pública, que hoy corresponde al Ministerio de Educación, cuya obra más significativa fue la primera Reforma de la Educación Superior en Colombia.

\section{EI Maestro Restrepo y las Universidades Republicanas}

La Revolución de Occidente de los siglos XVIII y XIX a través de las ideas de la Ilustración planteó la urgencia de la educación formal para las mayorías y la necesidad de llegar a la meta de una educación universal, libre y obligatoria. Se hacía necesaria asimismo, la formación de ciudadanos libres en estados democráticos y necesitados de unidad en sus respectivas naciones. La educación se consideraba como una fuente necesaria para fomentar la unidad nacional, la cohesión natural de los hombres que tienen un pasado común, y la formación de ciudadanos conocedores de sus derechos y obligaciones.Después de la Campaña Libertadora que culminó en la Batalla de Boyacá el 7 de agosto de 1819 y en la creación de la República de Colombia en el Congreso de Angostura el 17 de diciembre del mismo año, con la unión de Nueva Granada, Venezuela y Ecuador en un solo Estado Nacional integrado, se consideró importante la organización de las nuevas estructuras políticas, sociales, económicas, educativas y culturales.

Se generalizó la idea de una educación pública y oficial para que las mayorías de la población grancolombiana tuviera acceso a las escuelas, colegios y universidades, o sea en síntesis, una popularización y oficialización de la educación. Ante una educación elitista para las minorías que fue una característica de la época colonial hispánica, se hacía necesaria una educación popular para las mayorías del pueblo grancolombiano. La EDUCACION se convirtió en uno de los pilares con el cual los fundadores de la República se propusieron organizar el nuevo Estado Nacional, con el modelo democrático y republicano. 
El Congreso de Cúcuta de 1821 que dio las bases estructurales para el nuevo Estado Nacional de la República de Colombia, se preocupó por la Legislación sobre la educación en Colombia: ordenó la apertura de los Colegios oficiales que son los llamados Colegios Santanderinos y las casas de educación en todas las provincias; decretó la fundación de escuelas para las niñas y jóvenes en los conventos religiosos; determinó la creación de por lo menos una escuela de primeras letras en todas las ciudades, villas, parroquias y pueblos que tuvieran más de 100 vecinos; suministró locales con base en los conventos de religiosos, conventos menores que no tuviesen razón de existir por el corto número de sus integrantes; reformó los antiguos planes educativos y los unificó en el territorio nacional; ordenó la fundación de las Escuelas Normales para la formación del magisterio colombiano; ordenó la difusión del método Lancasteriano de educación o de enseñanza mutua para todo el territorio grancolombiano. ${ }^{31}$

El Vicepresidente de la Gran Colombia, el General Francisco de Paula Santander, llamado "El Hombre de las Leyes" se convirtió en el adalid de la educación pública, oficial y republicana. Fundó y organizó los llamados hoy Colegios Santanderinos y las escuelas primarias en los numerosos pueblos y parroquias de la Gran Colombia. Santander pensó que para la consolidación nacional y el progreso de Colombia, es necesaria la educación ciudadana. Según sus ideas, "la educación debe ser la primera empresa del Estado, y la más importante para la formación de las jóvenes generaciones colombianas."

En la reorganización de la Instrucción Pública que se hizo en la Gran Colombia mediante la Ley del 18 de marzo de 1826, se dispuso la organización de las UNIVERSIDADES PÚBLICAS, de carácter oficial, financiadas directamente por el Gobierno grancolombiano. Son las llamadas Universidades republicanas que presentan los rasgos de instituciones superiores públicas y laicas organizadas y supervisadas por el Estado Nacional. El Gobierno del Vicepresidente Santander nombró al Dr. José Félix de Restrepo como Director General de Instrucción Pública, o Director General de Estudios, que hoy corresponde al Ministerio de Educación Nacional. Fueron nombrados adjuntos los doctores Vicente Azuero y Estanislao Vergara. Mediante el Decreto del 18 de marzo de 1826 que autorizó al Poder Ejecutivo para formar el plan de estudios, el Senado y la Cámara de Representantes reunidos en Congreso, decretaron lo siguiente:

Artículo $1^{\circ}$. El Poder Ejecutivo formará y mandará llevar a efecto el plan que provisionalmente debe observarse para el establecimiento de escuelas

\footnotetext{
31 Ibídem, p. 179.
} 
y universidades y arreglo general y uniforme en ellas de la enseñanza.

Artículo $2^{\circ}$. La Dirección General de Instrucción Pública, reuniendo los datos generales, formará el plan y arreglos permanentes, los que pasará al Poder Ejecutivo, y éste, con su informe al Congreso, para su aprobación.

Artículo $3^{\circ}$. Al efecto se devolverá al Poder Ejecutivo el plan para el establecimiento de las Universidades y arreglo uniforme de la instrucción pública en Colombia, con todos los antecedentes con que lo pasó al Congreso, y con los demás documentos que existen en la Secretaría del Senado sobre la materia. ${ }^{32}$

Lo anterior señala que quien delineó y redactó con sus ideas educativas el Plan de Estudios para la creación de las Universidades Públicas fue el Dr. José Félix de Restrepo, en su condición de Director General de Instrucción Pública. En la Ley General de creación de las primeras Universidades públicas, que corresponde a la Primera Reforma Universitaria de Colombia, se aprobó que en la capital de cada Departamento de Colombia, o en la del cantón más proporcionado por su localidad y circunstancias, haya una Universidad o escuela general en que se adquieran los conocimientos. Se aprobaron las Universidades Centrales en las capitales de los Departamentos de Cundinamarca (Nueva Granada), Venezuela y Ecuador. Corresponden a la Universidad Central de Bogotá, la Universidad Central de Caracas y la Universidad Central de Quito. También se crearon las siguientes Universidades Departamentales regionales: Universidad de Boyacá en Tunja; Universidad del Cauca en Popayán y Universidad del Magdalena en Cartagena de Indias. ${ }^{33}$

Algunos aspectos de organización de los estudios fueron considerados en la Ley de 1826 sobre la organización y arreglo de la instrucción pública. Se aprobó que la enseñanza en las escuelas generales se divida en muchos cursos, a fin de que el sistema entero de las ciencias forme un curso completo de estudios y que los discípulos puedan según su talento y aplicación, ganar dos o más cursos al mismo tiempo. Se acordó que para la clase de Literatura: de lengua francesa e inglesa, de lengua griega, del idioma de los indígenas que prevalezca en cada departamento o que estime más conveniente la subdirección respectiva, de gramática latina combinada con la castellana, de literatura y bellas artes, y de elocuencia y poesía. Para las Universidades Centrales se

\footnotetext{
32 Ibídem, pp. 178-179

${ }^{33}$ Sobre la educación en la Gran Colombia, véanse las siguientes obras: OCAMPO LÓPEZ, Javier. (1987): Santander y la Educación. Tunja, Colegio de Boyacá; ECHEVERRI, Alberto S. (1989): Santander y la Instrucción Pública. Bogotá, Foro Nacional por Colombia-Universidad de Antioquia; BUSHNELL, David. (1966): El Régimen de Santander en la Gran Colombia, Bogotá, Tercer Mundo.
} 
aprobaron para la clase de Literatura los cursos de Historia literaria, antigua y moderna y Bibliografía.

Se aprobaron las clases de Filosofía y Ciencias naturales: de matemáticas, de física, de geografía y cronología, de lógica, ideología y metafísica, de moral $\mathrm{y}$ derecho natural, de historia natural, en sus tres reinos; de química y física experimental. Para las Universidades Centrales se aprobaron también los cursos de astronomía y mecánica analítica y celeste, botánica y agricultura, zoología, mineralogía, arte de minas y geognosia. Para las clases de Jurisprudencia y Teología: de principios, de legislación universal, de instituciones e historia, de derecho civil romano, de derecho patrio, de derecho público y político y de constitución; de economía política, de derecho público eclesiástico, de instituciones canónicas, de historia eclesiástica, fundamentos de la religión y lugares teológicos, de instituciones teológicas y morales de Sagrada Escritura; y estudios apologéticos de la religión.

Se aprobó que las Universidades Centrales tengan una Escuela de Medicina en la cual se enseñe medicina, cirugía y farmacia. Las cátedras serán las siguientes: anatomía general y particular, fisiología e higiene, patología general y anatomía patológica; terapéutica y materia médica, clínica médica, cirugía y clínica quirúrgica, farmacia, farmacia experimental y medicina legal y pública. En las Escuelas de Medicina habrá una biblioteca pública, un anfiteatro y gabinetes anatómicos, un laboratorio químico y farmacéutico, una colección de instrumentos quirúrgicos y un jardín de plantas medicinales. Se decretó que en los pueblos mineros se podrán fundar escuelas especiales de minería en donde se enseñe la mineralogía, geognosia, química aplicada a los ensayos o docimástica, fundición y amalgamación; además geometría práctica o subterránea, física y mecánica aplicada a las máquinas respectivas.En las ciudades que son puertos marítimos se podrían fundar Escuelas especiales de astronomía y navegación, arte de construcción naval, artillería, de ingenieros geógrafos, cosmografía, hidrografía de minas, comercio, agricultura experimental $\mathrm{y}$ bellas artes.

Se ordenó que en la capital de la República se funde un Museo y a su alrededor la creación una Escuela de aplicación en donde se enseñe arquitectura civil, fortificación, dibujo topográfico y de paisaje, geometría descriptiva con todas sus aplicaciones y otras. Se aprobó que en cada Universidad se organice una biblioteca pública, un gabinete de historia natural, un laboratorio químico y un jardín botánico, con los asistentes necesarios. En las Universidades habrá una imprenta para imprimir los libros elementales y de más uso. Se fundará en cada Universidad una Academia de emulación, cuyo principal objeto sea el 
fomento de las bellas letras y ciencias naturales.En las Universidades habrá exámenes públicos y generales por lo menos cada año, en diferentes días y actos. Los cursantes que sobresalgan en estas pruebas recibirán premios de los fondos de las universidades que se clasificarán en el plan de su establecimiento. Los estudiantes más sobresalientes se enviarán a Europa para que perfeccionen sus conocimientos en diferentes profesiones; ellos tendrán una pensión anual que destinará el Congreso por el tiempo necesario para complementar su instrucción en las ciencias o en las artes útiles. Una vez terminados los estudios, tendrán la obligación de ingresar a Colombia y emplearse en la enseñanza pública a juicio de la Dirección General.

Se estableció que las cátedras en las Universidades deben obtenerse por oposición pública. Los opositores tendrán los grados académicos correspondientes a cada profesión. El examen de los opositores a cátedras se hará en público y por un cuerpo examinador compuesto por lo menos de cinco catedráticos o doctores de la facultad, nombrado cada dos años por la Dirección General y de las subdirecciones en su respectiva demarcación. Los catedráticos serán nombrados por el Poder Ejecutivo a través de la Dirección General o de los Intendentes.

Las rentas para la enseñanza pública se dotarán de los fondos que se asignen por parte del gobierno nacional y de los fondos que destinen los pueblos para la educación. Las rentas de las Universidades existentes en Colombia; las dotaciones de cátedras existentes en cualesquiera seminarios o colegios correspondientes a las facultades que hayan de enseñarse sólo en las Universidades. Los fondos destinados por cualesquiera fundadores, testadores o donadores para la educación y enseñanza pública. Los principales de temporalidades de ex-jesuitas que se destinaron por los fundadores o testadores para la enseñanza pública. Las rentas de los conventos suprimidos en las respectivas provincias del departamento. Las rentas de las respectivas canonjías suprimidas y aplicadas antes a la Inquisición. Las fundaciones de capellanías y patronatos de legos. Los edificios de los conventos suprimidos $u$ otros nacionales que se destinen para las universidades, escuelas de medicina, colegios nacionales o establecimientos de enseñanza pública. Las bibliotecas públicas que en el día existan en Colombia correrán a cargo de las universidades con la calidad de públicas para el uso común. ${ }^{34}$

El Plan de estudios de 1826 que redactó el Dr. José Félix de Restrepo en cumplimiento del Decreto del 18 de marzo de 1826 establece algunos aspectos

\footnotetext{
${ }^{34}$ Decreto del 18 de marzo de 1826 que da potestad al Poder Ejecutivo para formar el Plan de Estudios.
} 
que complementaron la Ley del 18 de marzo, sobre la organización y arreglo de la instrucción pública. Se crearon las Juntas generales de las Universidades para tratar los asuntos administrativos y académicos de la institución. La Junta general estará integrada por el rector quien la preside; del vicerrector, catedráticos y doctores. La junta particular estará formada por el rector, vicerrector y seis catedráticos; se encargará de velar por la exactitud de la enseñanza y la el cumplimiento de los reglamentos y leyes académicas. Se establecieron las funciones del Rector, quien representará a la institución y cuidará de la observancia de las leyes académicas, haciéndolas cumplir y ejecutar puntualmente. El Rector será elegido en junta general a pluralidad absoluta de votos entre los catedráticos actuales o jubilados, o entre los doctores, si a favor de alguno de ellos se reunieren las dos terceras partes de los sufragios. La elección se hará el 20 de noviembre y el día $1^{\circ}$ de enero se posesionará solemnemente. Su período rectoral será de tres años. El Vicerrector reemplazará al Rector; será inspector especial y tiene a su cargo el buen orden y policía de la universidad; cuidará del aseo de la universidad con sus subalternos y llevará un registro de todos los catedráticos y cursantes.

La Universidad confiere los grados de bachiller, licenciado y doctor en jurisprudencia, medicina y teología. Se suprimieron los grados en filosofía. Los grados habilitan para diferentes efectos civiles y eclesiásticos. En la Ley se organizaron las matrículas y los exámenes para optar grados; asimismo los sistemas de calificaciones y los derechos de grados. Los catedráticos ingresarán a la Universidad mediante examen de oposición y serán nombrados por el gobierno. También se establecieron las normas para los cursantes o alumnos y para los certámenes públicos. Se acordó que los certámenes públicos se realicen en el mes de octubre, en los cuales cada catedrático sostendrá todas las materias que haya enseñado en el año, señalando para sostenerlos con acuerdo del rector y vicerrector a los cursantes más aprovechados, ninguno de los cuales se podrá excusar. Cada uno de los catedráticos hará por lo menos un certamen anual. En ninguno de ellos se defenderá proposición alguna que sea contraria a las leyes fundamentales y libertades de la República, a las libertades de la Iglesia colombiana, a la moral y a la decencia pública. Anualmente se distribuirán tres premios a los jóvenes que más se distingan en los certámenes de las universidades. En cada Universidad se nombrarán dos bedeles, quienes se ocuparán de la disciplina, el aseo y limpieza y de la organización de todos los certámenes de las Universidades.

En el Plan de estudios de 1826 se organizó la administración de las rentas de las universidades y los servicios de secretaría y archivo. En la misma forma, se reglamentaron los servicios de la biblioteca e imprenta y del museo, laboratorio 
químico y jardín botánico. En el capítulo XXII se dieron las bases para la organización general de las enseñanzas en la Universidad, distribuidas en Literatura y bellas artes, filosofía y ciencias naturales, medicina, jurisprudencia y teología. En el capítulo XXIII se dieron las bases para la organización de las cátedras de cada clase: Literatura y bellas artes, especificando las materias, los libros y los catedráticos; Lengua latina; Lengua griega; Idioma de los indígenas; literatura y bellas artes; Historia literaria y bibliográfica. Así explicó el Dr.José Félix de Restrepo la enseñanza de las letras:

\begin{abstract}
Artículo 152. Literatura y Bellas Letras. La enseñanza de la literatura y bellas comprende lo que se llama clase de retórica y poética, o un curso razonado de literatura y bellas letras en que se examinen los principios generales del gusto, del genio, de la crítica en todas las artes de la imaginación y en las tres nobles de la pintura, arquitectura y escultura. El catedrático enseñará la oratoria en sus diferentes acepciones, desde la sencillez del apólogo, hasta lo más sublime de la tragedia y epopeya y la parte de la imaginación. Hará conocer las diferentes épocas y el buen gusto, la literatura de las naciones antiguas y modernas, los profesores más célebres y las épocas en que se han distinguido. Estas lecciones se darán por el primer tomo de retórica y bellas letras de Hugo Blair, traducido al castellano por Bateux, y por el compendio de literatura antigua y moderna de la Harpe. Los discípulos harán la versión en castellano de las Instituciones de Quintiliano, de La Eneida de Virgilio, del arte poético de Horacio, de sus cartas y odas escogidas, y de Tácito, Tito Livio y Salustio. Los elementos de poesía se estudiarán por los principios de don Francisco Sánchez o por los del Rey, consultándose también la poética de Arístides y la de Horacio, leyendo los cursantes los mejores modelos en castellano. Para la mitología servirá la compuesta para uso de los liceos de Francia o el diccionario de Chompré. ${ }^{35}$
\end{abstract}

En la misma forma, el Dr. José Félix de Restrepo redactó los distintos cursos del Plan de Estudios de 1826: En la Clase de filosofía y ciencias naturales: Matemáticas, Física general y particular, Geografía y Cronología, Ideología o Metafísica, Moral y Derecho natural, Historia natural en sus tres reinos: mineralogía, botánica y zoología; Botánica y agricultura, Zoología, Química y Física experimental. En la Clase de Medicina, los cursos de Anatomía general, particular y anatomía patológica, Fisiología e Higiene, Nosología y patología, Terapéutica y farmacia, Clínica médica y quirúrgica. La Clase de Jurisprudencia, los cursos de Principios de Legislación universal y de Legislación civil y penal; Derecho público, político, constitución y ciencia administrativa; Historia e instituciones de derecho civil, romano y derecho patrio, Economía política, Derecho internacional o de gentes, Derecho público eclesiástico, instituciones canónicas y suma de concilios. En la Clase de

\footnotetext{
${ }^{35}$ Ley del 18 de marzo de 1826 por la cual se crearon las universidades públicas.
} 
Teología, los cursos de Fundamentos de la Religión, Sagrada Escritura, Instituciones de teología dogmática y moral.

Para cada una de las clases se plantea una síntesis metodológica y las obras más representativas para ser seguidas en los cursos. Para la lengua francesa, la gramática de Chatreau o la de Campany y el diccionario de Núñez Taboada y la gramática filosófica y literaria de Levisac; asimismo, textos originales de Hany, Say Cintant y otros Para la lengua inglesa, la de Cobbet y el diccionario de Newman, con textos originales de Hugo Blair, las cartas Junio, Adisson, la historia de Hume y otros autores de primera clase. Para la Lengua latina, aconseja la gramática latina de Pombo, el diccionario latino de Valbuena y el de la academia española; las obras de Cicerón y Cornelio Nepote, la gramática y ortografía de la Academia española; las fábulas de Fedro, los comentarios de Julio César, la historia de Quinto Curcio, las oraciones escogidas de Tacio, los tristes de Ovidio y las bucólicas de Virgilio. Consultar la prosodia de G.Rey compuesta para los liceos de Francia. Los maestros consultarán las obras gramaticales de César Dumarsais, las de Sánchez Broces, el método de Port Royal y la gramática latina de Guenoult. Para la Lengua griega, la gramática griega de J.B. Barbieri, la de Burnouf o la de Gail, las fábulas de Esopo, los diálogos de Luciano, las oraciones escogidas de Isócrates y Demóstenes, de Tucídides, Homero y Píndaro. Para la Historia literaria y bibliográfica recomendó la literatura del abate Juan Andrés y para la Bibliografía, el diccionario bibliográfico y el nuevo diccionario histórico.

Para las Matemáticas se recomendó el curso de Lacroix, con las obras de Lagrange, Bossuet, Garnier, Hachette y demás sabios matemáticos. Para la Física general y particular se recomendaron las obras de Hany, Libes y Biot; asimismo el curso de meteorología de Garriga. Para el curso de Geografía y cronología se recomiendan las lecciones de geografía de Maltebrun, Mantelle o la de Pinkreton; los elementos de cronología por el raciocinio del padre Petau. Para el curso de Ideología o metafísica recomendó la ideología de Destutt de Tracy y las obras de Condillac. El Derecho natural por las obras de Felice.

Para las clases de mineralogía, el tratado de mineralogía de Brongniart, las obras de Hany, de Werbes y de Duluc. La geognosia por la obra de D'Aubuisson. Para la Botánica los ejercicios de botánica de Philibert, Lamarck, Decandole, Ventenal y otros. Para la Agricultura servirán las tablas metódicas de Dossier, los elementos de agricultura de Duhame, la fisiología vegetal de Sevenier, las obras de Parmentier, Chaptal y otras. Para el curso de Zoología, recomendó la zoología analítica de Dumeril; la historia de Bufón y el sistema de Linneo, indicando los trabajos de Cubier, Lamarck y otros sabios. Para la Química las obras de Bouillon y Lagrang; los elementos de química de Chaptal, de Fourcroy, Bernhotel, Lavoisier 
y los anales químicos. La clasificación de Tohnarp por Caventou, y traducida por Llorente.

Para el curso de Anatomía recomendó el de Boyer, la anatomía general de Richat con notas de Beclard, la anatomía descriptiva de Cloquet y la de Marjolin. Para enseñar la fisiología servirá la obra de Magendie y el tratado de la vida y de la muerte con notas del mismo autor; los elementos de Richerand, con las obras de Dumas y Halle. Para la Higiene servirá la de Tourtelle, el tratado de higiene pública de Foderé y el de Mahon. Para la cátedra de Nosología servirá la obra de Richerand, los elementos de patología de Chomel, traducidos al castellano; la patología de Tourtelle, y los aforismos de Hipócrates, comentados por Goiter. El catedrático podrá consultar también a Broussais, a Magendie y otros autores célebres. La Terapéutica se estudiará por la obra de Alibert o por la de Rochefort. Para la Farmacia teórica y práctica la obras de Verey, Carbonell y Fernández, el diccionario de Hernández de Gregorio y Llorente y el maestro Morelot. La Clínica médica se enseñará por la obra de Pinell, las observaciones clínicas de Stoll y la obra de Morgani; para la Clínica quirúrgica servirán la obra de Boyer y los elementos de Bell. Para la Obstetricia el curso teórico y práctico de Cauperón y el curso de partos de madame Roivin. Para la medicina legal podrán servir la obra de medicina legal y judiciaria de Bellard y la de Bellaz, consultándose las obras de Foderé y de Orfila.

En la Clase de Jurisprudencia, se aconseja para el curso de Principios de legislación universal y de legislación civil y penal, los tratados de legislación civil y penal de Jeremías Bentham; también se estudiarán las lecciones de Rey de Grenoble. El derecho público político se enseñará por la obra elemental de Constant, mientras que hay otra más propia para una República. Se explicará la Constitución de Colombia. Se consultarán los escritos de Montesquieu, Mably, Tracy, Fritot y demás obras clásicas. Sobre la Legislación administrativa se consultarán las obras de Bonis y Poiriez. La Historia del derecho civil romano se estudiará por el compendio de antigüedades romanas de Heinnecio, y las instituciones por Vinio, castigado por Don Juan de Sala. El derecho patrio o las leyes positivas de Colombia y su legislación civil y criminal deberán estudiarse por sus propios códigos. Las antiguas leyes españolas se estudiarán por la obra de don Antonio Sotelo. Los principios del derecho español se estudiarán por la ilustración del derecho real de España escrita por don Juan de Sala. La Economía política se estudiará por la obra clásica de Juan Bautista Say. El Derecho Internacional o de Gentes se estudiará por la obra de Wattel, el manual diplomático de Martens y las obras de Burlamaqui y Azuni.

El Derecho público eclesiástico por la obra de Derecho eclesiástico de Segismundo Lakis. Se consultarán las obras de Venespen, Marca, Bossuet y Covarrubias y las instituciones de Cavalari. La disciplina eclesiástica se estudiará 
por la obra de Pellizia o la de Tomasini. La Historia eclesiástica, por un resumen de la de Ducreux o Gmeneri, consultando las obras de Fleuri y Martenne. La suma de concilios podrá estudiarse por la obra de Larrea o la de Carranza. En el curso de Fundamentos de la Religión se recomienda la obra Tractatus de vera religione de Ludovico Bailly y las delicias de la religión de Laumorete. Para los lugares teológicos la obra de Melchor Cano, y el primer tomo del curso de León. Los estudios apologéticos de la religión se darán por la obra de Bergier, el apologista y las prescripciones de Tertuliano Gourey. La Sagrada Escritura se enseñará por el aparato bíblico del Lami, las disertaciones del abate Vence y los prolegómenos y preliminares a la sagrada escritura de San Jerónimo. Las instituciones de Teología dogmática y moral se estudiarán por las lecciones de teología dogmática y moral por Habert o por el padre Tomás Charles. El catedrático consultará particularmente la Suma de Santo Tomás y las obras de otros teólogos recomendados. ${ }^{36}$

En el Plan de estudios que fue encomendado para su redacción y presentación al Gobierno de la Gran Colombia al Dr.José Félix de Restrepo, se especificó sobre la Academia de emulación para fomentar el estudio en los diferentes ramos de las bellas artes y de las ciencias naturales; la academia de derecho práctico, la distribución de los cursos que se han de ganar y años que se han de estudiar para obtener grados; los estudios necesarios para los médicos y la facultad de medicina; y los estudios necesarios para los abogados. Para la obtención de los libros fundamentales para la enseñanza en las Universidades, el Plan de estudios en su artículo 230 señala que es de urgente necesidad que "las escuelas, colegios y universidades sean provistos, con la mayor brevedad posible, de los libros elementales más necesarios, bien cuidando de su impresión, bien pidiéndolos a Europa, o bien, finalmente, excitando a algunos comerciantes colombianos o extranjeros para que los traigan por su cuenta con el fin de venderlos a los estudiantes".

La influencia de las Universidades Centrales se estableció en la siguiente forma: la Universidad Central de Bogotá, con influencia en los departamentos de Cundinamarca, Boyacá, Magdalena, Istmo y Cauca; la Universidad Central de Caracas, con influencia en los departamentos de Venezuela, Maturín, Orinoco y Zulia; y la Universidad Central de Quito se extenderá a los departamentos de Ecuador y Guayaquil. ${ }^{37}$ La Universidad Central de Bogotá. Mediante la Ley del 18 de marzo de 1826 y por iniciativa del Vicepresidente de la República, General Francisco de Paula Santander fue creada oficialmente la Universidad Central en Bogotá, la primera Universidad republicana oficial que se creó en Colombia. Mediante dicha Ley también se crearon las Universidades Centrales de Caracas y Quito. Mediante el Decreto

\footnotetext{
36 Ibídem, pp. 17-26.

37 Artículo 152. Literatura y Letras. Plan de Estudios de 1826. Redactado por el Doctor José Félix de Restrepo.
} 
del 3 de octubre de 1826 se reglamentó el Plan de Estudios, expedido por el Vicepresidente Santander y el Secretario del Interior, Don José Manuel Restrepo.El 25 de diciembre del año 1826 se instaló solemnemente en la Capilla de San Carlos, hoy San Ignacio, la Universidad Central en Bogotá, la primera Universidad republicana de carácter oficial y pública que se creó en Colombia. Al acto solemne, que se realizó a las 11 de la mañana, asistieron el Vicepresidente de la República, General Francisco de Paula Santander, los secretarios del despacho y la mayor parte de las autoridades y personas notables de la capital. El Director General de Estudios, Doctor JOSÉ FÉLIX DE RESTREPO, en nombre de la República, tomó el juramento al Rector nombrado, doctor Fernando Caycedo y Flórez, al Vice-Rector doctor José María Castillo y Rada, y al secretario de la Universidad, doctor Alejandro Osorio. En seguida el mismo Director de Estudios pronunció un discurso alusivo al importante acto de instalación de la primera Universidad republicana de Colombia.

Concluido este acto, toda la concurrencia se trasladó al salón en que se hallaba colocada la biblioteca pública y allí el Secretario del Interior, el doctor José Manuel Restrepo procedió a instalar la Academia Nacional, creada para establecer, fomentar y propagar en Colombia el conocimiento y perfección de las artes, de las letras, de las ciencias naturales y exactas, de la moral y de la política. En la Academia fue nombrado su primer director el Dr. José Félix de Restrepo; y Secretario de la Academia el señor Pedro Acebedo. La Academia nombró una comisión compuesta del director, el secretario y el señor Jerónimo Torres para presentar un proyecto del reglamento orgánico. ${ }^{38}$

La Universidad Central de Bogotá se integró con varias Facultades que funcionaban en distintas instituciones: las Facultades de Jurisprudencia y Medicina en el Colegio Mayor de San Bartolomé; las Facultades de Filosofia y Literatura en el Colegio Mayor del Rosario y Teología en el Seminario. Su primer Rector fue el Doctor Fernando Caycedo y Flórez; entre los primeros catedráticos figuran ilustres personalidades, destacando las siguientes: los doctores Vicente Azuero, José Félix de Restrepo, José María del Castillo y Rada, Ignacio de Herrera, Francisco Soto, Tomás Tenorio, Estanislao Vergara y otros. Para la organización de la Universidad se le asignaron los siguientes edificios: la iglesia de San Carlos, que fue de los jesuitas; el edificio que servía para el Colegio de San Bartolomé y la casa y solar contiguos. ${ }^{39}$

La Universidad Central de Bogotá tuvo su actividad académica hasta el 15 de mayo de 1850 , cuando en nombre de la libertad de enseñanza y de igualdad

\footnotetext{
38 Ibídem. pp. 38-82.

39 PLAN DE ESTUDIOS 1826. En: Archivo General de la Nación. Sección República. Archivo Histórico Restrepo. Fondo III. Instrucción Pública. Tomo I, 1821-1847, p. 178-201.
} 
democrática se extinguieron los títulos académicos y las Universidades oficiales. Las únicas instituciones de educación superior que continuaron fueron el Colegio Mayor del Rosario y el Colegio Mayor de San Bartolomé, cuya trayectoria histórica viene desde el siglo XVII. Mediante la Ley del 22 de septiembre de 1867, aprobada por el Congreso Nacional y sancionada por el Presidente Santos Acosta, se fundó la Universidad Nacional de Colombia. Surgió con las Escuelas de Derecho, Medicina, Ingeniería, Ciencias Naturales, Literatura y Filosofía y Artes y Oficios. Su primer Rector fue el Dr. Ezequiel Rojas, quien fue reemplazado por el Dr. Manuel Ancízar. Ello señala que en la Historia de la Universidad Nacional en el siglo XIX se tienen en cuenta dos etapas: la primera de la Universidad Central, desde 1826 hasta 1850; y la segunda a partir del año 1867 cuando se creó la Universidad Nacional de Colombia.

La Universidad del Cauca. Mediante el Decreto del 24 de abril del año 1827, firmado en Bogotá por el Vicepresidente Francisco de Paula Santander, se creó la Universidad del Cauca en Popayán. El Primer Rector fue don José Antonio Arroyo; y el Vicerrector, el doctor Manuel José Mosquera, canónigo de la Iglesia Catedral. Sus primeros catedráticos fueron : Joaquín Mosquera en legislación civil y penal; Fortunato Manuel de Gamba, en Derecho Constitucional y Ciencia Administrativa; Joaquín Fernández de Soto en Derecho Público; Lino de Pombo, en Matemáticas; Joaquín Cajiao, en Medicina Legal e Higiene Pública; Dr. José Antonio Arroyo en Economía; Dr. Manuel José Mosquera en Derecho Civil y Patrio; Dr. Juan N. Aguiar, en Derecho Internacional; Dr. José Vicente Cobo en Gramática; Dr. Rufino Cuervo en Legislación civil y penal; Dr. Juan Manuel María de Rada y Mosquera, Profesor de Teología Dogmática Fray Manuel Granda y otros.

El Libertador Simón Bolívar expidió el Decreto del 6 de octubre de 1827, por el cual se señalaron las rentas para la vida económica y académica de la Universidad. Entre los bienes raíces pasaron a la Universidad, el Convento de los Dominicos, el Convento de San Agustín, el extinguido Convento de los Padres Camilos o de la Buena Muerte, la Hacienda de Quilcacé, los derechos de dominio de la mina de Naya y otros bienes raíces y capitales. Bajo su dependencia fueron asignados los Colegios Santanderinos de Santa Librada de Cali y los Colegios de Buga, Cartago y el San Agustín de Pasto. Cuando se iniciaron los estudios universitarios, Popayán sufrió el terremoto del 16 de noviembre de 1827, que llenó la ciudad de ruinas. Uno de los profesores de la Universidad del Cauca, el Dr. Joaquín Mosquera reemplazó al Libertador Simón Bolívar en la Presidencia de Colombia.

Le correspondió a la Universidad del Cauca afrontar la situación del Cauca ante las guerras civiles y los problemas políticos de la Nueva Granada o Colombia. En los siglos XIX y XX, la Universidad del Cauca tuvo fama por su profundo humanismo y 
espíritu grecolatino de gran cultura. La Universidad de Boyacá. Mediante el Decreto Nacional del 30 de mayo de 1827, firmado por el Vicepresidente Francisco de Paula Santander. se creó la Universidad de Boyacá en la ciudad de Tunja. Se le aplicaron las rentas destinadas al Colegio de Boyacá, "cuyas cátedras quedarán incorporadas en su totalidad a la expresada Universidad"; asimismo, las rentas del Convento de Santo Ecce Homo. Fue designado Rector de la Universidad de Boyacá, el Dr. José Ignacio de Márquez; sin embargo, por sus ocupaciones políticas no pudo aceptar en forma definitiva, por lo cual fue nombrado Rector en propiedad el Dr. Bernardo María de la Motta, con quien se instaló solemnemente la Universidad de Boyacá, el 8 de diciembre de 1827 en el antiguo claustro de San Agustín.

El Libertador Simón Bolívar expidió el Decreto del 5 de enero de 1828, mediante el cual se organizó la Universidad de Boyacá y se destinó el edificio del Colegio de Boyacá para su ubicación. En esta Universidad funcionaron las siguientes carreras: Jurisprudencia, Medicina, Filosofía y Letras, Ciencias Naturales, Ingeniería y Artes y Oficios. Los primeros catedráticos que nombró el Libertador Simón Bolívar en la Universidad de Boyacá, fueron los siguientes: Dr. Juan Gualberto Gutiérrez para las cátedras de anatomía general, particular, descriptiva; Dr. Juan Nepomuceno Riaño para las cátedras de Derecho público político, constitución y ciencia administrativa; asimismo, fueron nombrados otros profesores. El 9 de abril de 1829 el Libertador nombró Rector de la Universidad de Boyacá al cura de Siachoque, Dr. Rafael Solano y Vicerrector al Dr. Juan Nepomuceno Riaño. ${ }^{40}$

La Universidad del Magdalena e Istmo. Mediante el Decreto del 6 de octubre de 1827 se creó la Universidad del Magdalena e Istmo, con sede en la ciudad de Cartagena. Según el acta de instalación de esta Universidad, el 11 de noviembre de 1828, el objetivo central de esta institución fue hacer de ella "un instrumento central en el fortalecimiento de la nación y de las virtudes ciudadanas; además de formar el grupo del Estado". Esta institución corresponde hoy a la Universidad de Cartagena.

\section{CONCLUSIÓN}

En este proceso histórico de la primera Reforma Universitaria en Colombia, la labor educativa del Maestro Dr. José Félix de Restrepo fue de gran trascendencia, pues gracias a su experiencia y alto nivel humanístico y pedagógico, se organizaron las primeras Universidades Republicanas en la Gran Colombia. Este gran "Maestro de los Precursores", llamado por Santander "Padre de las Luces de la Nueva Granada" se convirtió en uno de los grandes educadores en los orígenes de la consolidación nacional; quien dio las orientaciones para la organización y consolidación

${ }^{40}$ Acto de instalación de la Universidad Central. Gaceta de Colombia, Bogotá, número

272, Diciembre 31 de 1826, p. 2. 
de las primeras Universidades. Con su sabiduría pedagógica como "Maestro de los Precursores de la Independencia" y con su formación jurídica y social que lo llevaron a defender la abolición de la esclavitud, en la independencia y la libertad, el Dr. José Félix de Restrepo se convirtió en el "faro de luz" de la democracia y la educación republicana en los orígenes de Colombia.

\section{FUENTES}

ACTO DE INSTALACIÓN DE LA UNIVERSIDAD CENTRAL. Gaceta de Colombia, Bogotá, número 272, Diciembre 31 de 1826.

CARTA DEL OBISPO DE POPAYÁN DON JERÓNIMO ANTONIO DE OBREGÓN al Dr. José Félix de Restrepo, ofreciéndole la Cátedra de Filosofía para el Seminario de Popayán, en Vida y escritos del doctor José Félix de Restrepo, recopilada por el Dr. HERNÁNDEZ DE ALBA, Guillermo.

DECRETO del 18 de marzo de 1826 que da potestad al Poder Ejecutivo para formar el Plan de Estudios.

DE RESTREPO, José Félix. (1814): "Proyecto de Ley sobre la manumisión de la posteridad de los esclavos africanos y sobre los medios de redimir a sus padres". Rionegro, 20 de febrero de 1814.

RESTREPO, Carlos. (1970): José Félix de Restrepo. Jurisconsulto, humanista y hombre de Estado. Bogotá, Editorial Nelly.

DE RESTREPO, José Félix. (1971): “Oración para el ingreso a los estudios de filosofia”, pronunciado por el Dr. José Félix de Restrepo en el Real Seminario de San Francisco de Asís de Popayán en octubre de 1791", en Papel Periódico, viernes 16 de diciembre de 1791.

FÉLIX DE RESTREPO, José. (1821): “Discurso sobre la manumisión de esclavos, pronunciado en el soberano Congreso de Colombia reunido en la Villa del Rosario de Cúcuta en el año 1821.

DE RESTREPO, José Félix. (2002): Obras completas. Contextualización y notas por Daniel Herrera Restrepo. Bogotá, Universidad Santo Tomás. Facultad de Filosofía.

Partida de bautismo de José Félix de Restrepo. 28 de noviembre de 1760.

Plan de estudios 1826. En: Archivo General de la Nación. Sección República. Archivo Histórico Restrepo. Fondo III. Instrucción Pública. Tomo I, 1821-1847, p. 178-201.

Ley del 18 de marzo de 1826 por la cual se crearon las universidades públicas.

\section{REFERENCIAS}

BUSHNELL, David. (1966): El Régimen de Santander en la Gran Colombia, Bogotá, Tercer Mundo.

ECHEVERRI, Alberto S. (1989): Santander y la Instrucción Pública. Bogotá, Foro Nacional por Colombia-Universidad de Antioquia.

ESCOBAR VALENZUELA, Gustavo. (1990): La Ilustración en la filosofia latinoamericana. México, Editorial Trillas.

Rhela. Vol. 14. Año 2010, pp. $9-60$ 
FRITZ, Valiavec. (1964): Historia de la Ilustración en Occidente. Madrid, Ediciones RIALP.

CASSIRER, Ernest(1972): Filosofia de la Ilustración, México, Fondo de Cultura Económica.

CARDIEL REYES, Raúl. (1964): Los filósofos modernos en la Independencia Latinoamericana. México, UNAM.

GALLO MARTÍNEZ, Luis Álvaro. (2007): Apuntes biográficos de Restrepo. Bogotá, Editor impresor Luis Álvaro Gallo Martínez.

GÓMEZ HOYOS, Rafael. (1999): La Revolución Granadina de 1810. Ideario de una Generación $y$ de una época 1781-1821. Bogotá, Editorial Temis.

HERRERA RESTREPO, Daniel. (1989): El pensamiento filosófico de José Félix de Restrepo. Bogotá, Colcultura.

HILARIO LÓPEZ, José. (1969): Memors. Medellín, Editorial Bedout, Bolsilibros Bedout.

MONTOYAY MONTOYA, Rafael. (1961): Obras completas de José Félix de Restrepo. Medellín, Editorial Bedout.

MORENO Y ESCANDÓN, Francisco. (1774-1779): "Plan de Estudios. Método provisional e intensivo de los estudios que han de observar en los Colegios de Santafé, por ahora, y hasta tanto que se erige Universidad Pública, o su Majestad no dispone otra cosa", en Boletín de Historia y Antigüedades (Bogotá), Academia Colombiana de Historia

OSPINA RODRÍGUEZ, Mariano. (1936): José Félix de Restrepo y su época. Bogotá, Publicaciones del Ministerio de Educación Nacional.

OCAMPO LÓPEZ, Javier. (1999): El proceso ideológico de la emancipación en Colombia. Bogotá, Editorial Planeta.

OCAMPO LÓPEZ, Javier. (1987): Santander y la Educación. Tunja, Colegio de Boyacá.

RESTREPO CANAL, Carlos. (1970): José Félix de Restrepo. Jurisconsulto, humanista y hombre de Estado". Bogotá, Editorial Nelly.

RESTREPO, Carlos. (1938): Canal La libertad de los esclavos en Colombia"'(Leyes de Manumisión). Bogotá, Imprenta Nacional.

SOTO, Diana. (1995): y otros, La Ilustración en América Colonial. Madrid, Ediciones Doce Calles.

VARGAS SÁEZ, Pedro, C.M. (1945): Historia del Real Colegio Seminario de San Francisco de Asís de Popayán. Academia Colombiana de Historia. Biblioteca de Historia Nacional. Vol. LXXV. Bogotá, Editorial A.B.C.

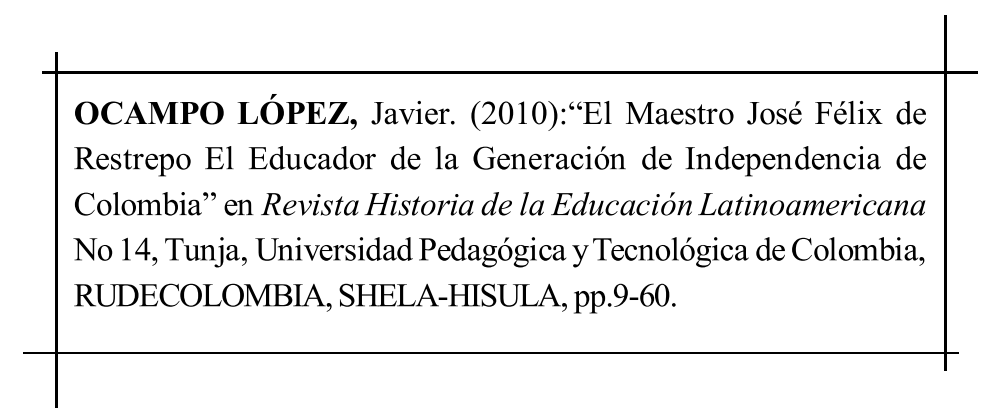

Rhela. Vol. 14. Año 2010, pp. 9 - 60 